IZA DP No. 9282

Relative Income and Life Satisfaction of Turkish Immigrants:

The Impact of a Collectivistic Culture

Devrim Dumludag

Ozge Gokdemir

Maarten C.M. Vendrik

August 2015 


\title{
Relative Income and Life Satisfaction of Turkish Immigrants: The Impact of a Collectivistic Culture
}

\author{
Devrim Dumludag \\ Marmara University and Maastricht University \\ Ozge Gokdemir \\ Istanbul University and Maastricht University \\ Maarten C.M. Vendrik \\ Maastricht University, ROA, IZA and EHERO
}

Discussion Paper No. 9282

August 2015

IZA

P.O. Box 7240

53072 Bonn

Germany

Phone: +49-228-3894-0

Fax: +49-228-3894-180

E-mail: iza@iza.org

Any opinions expressed here are those of the author(s) and not those of IZA. Research published in this series may include views on policy, but the institute itself takes no institutional policy positions. The IZA research network is committed to the IZA Guiding Principles of Research Integrity.

The Institute for the Study of Labor (IZA) in Bonn is a local and virtual international research center and a place of communication between science, politics and business. IZA is an independent nonprofit organization supported by Deutsche Post Foundation. The center is associated with the University of Bonn and offers a stimulating research environment through its international network, workshops and conferences, data service, project support, research visits and doctoral program. IZA engages in (i) original and internationally competitive research in all fields of labor economics, (ii) development of policy concepts, and (iii) dissemination of research results and concepts to the interested public.

IZA Discussion Papers often represent preliminary work and are circulated to encourage discussion. Citation of such a paper should account for its provisional character. A revised version may be available directly from the author. 


\section{ABSTRACT}

\section{Relative Income and Life Satisfaction of Turkish Immigrants: The Impact of a Collectivistic Culture ${ }^{*}$}

This study examines the effects of social comparison with a wide range of reference groups on the life satisfaction of Turkish immigrants in the Netherlands. For two sets of ethnic and life-domain reference groups, results are obtained that deviate from the findings of recent studies and that suggest the impact of the collectivistic subculture of the Turkish immigrants. Perceived importance of income comparison with Dutch natives is positively correlated to life satisfaction, supporting an interpretation of this comparison as a positive emancipatory stimulus in the pursuit of self-improvement of the Turkish immigrants. Perceived importance of income comparison with relatives in the Netherlands is positively correlated to life satisfaction as well, which can be interpreted in terms of an underlying feeling of connectedness with one's relatives. On the other hand, Turkish immigrants who have a higher household income than relatives are significantly less satisfied with their life, suggesting the unattractiveness of deviating too much from one's relatives. For other reference groups some interesting results are obtained as well.

JEL Classification: I31, Z13, J15

Keywords: happiness, life satisfaction, relative income, social comparison, collectivistic, immigrants

Corresponding author:

Maarten Vendrik

Department of Economics

School of Business and Organization

Maastricht University

P.O. Box 616

6200 MD, Maastricht

The Netherlands

E-mail: m.vendrik@maastrichtuniversity.nl

\footnotetext{
* The authors would like to thank the Scientific and Technological Research Council of Turkey (TÜBITAK - no: 2219) and the Council of Higher Education (YÖK) for their financial support of the research project for this paper, and the Foreign Ministry of Foreign Affairs of Turkey, the Turkish Consulate at Rotterdam, the AE1 section of the School of Business and Organization (SBE) at Maastricht University, the Dutch Organization for Scientific Research (NWO), Ineke Bijlsma, and HardZout for their valuable support. We are also grateful to Martin Carree, Richard Easterlin, John de Figueiredo, Andries de Grip, Erzo Luttmer, Olivier Marie, Raymond Montizaan, Andrew Oswald, Barkley Rosser, Ruut Veenhoven, Rolf van de Velden, and participants of the EALE 2014 conference in Ljubljana, the EHERO seminar in Rotterdam, the DUHR seminar in Maastricht, and the ESPE 2015 conference in Izmir for helpful comments.
} 


\section{Introduction}

People compare themselves with others. Moreover, such social comparison has been shown to have significant effects on subjective well-being, especially in the numerous studies on relative income and happiness (e.g., Clark and Oswald, 1996; McBride, 2001; Van Praag and Ferrer-i-Carbonell, 2004; Ferrer-i-Carbonell, 2005; Luttmer, 2005; Senik, 2009; Layard et al, 2010; D'Ambrosio and Frick, 2012; Vendrik, 2013). However, a limitation of many of these studies is that they do not have direct information on the identity of the social groups people compare themselves to, and hence have to assume hypothetical reference groups in terms of observable criteria like age, educational level, sex, and region of residence. Moreover, assumptions have to be made which are the relevant income levels in these reference groups for the social comparison, and more generally social interaction. ${ }^{1}$ In reaction to this state of research, some recent studies of relative-income effects on happiness (Mayraz et al., 2009; Clark and Senik, 2010; Goerke and Pannenberg, 2013) have employed direct survey information about perceptions of the importance of social reference groups and one's own income relative to them. ${ }^{2}$ The studies of Mayraz et al. (2009) and Goerke and Pannenberg (2013) are the most advanced and use recent waves of SOEP data for Germany. Mayraz et al. (2009) find (marginally) significant relative income effects only for males and the reference groups of same sex and same profession (in a regression which combines all distinguished reference groups) while Goerke and Pannenberg (2013) present robust significant relative income effects only for colleagues at work, same profession and friends (in separate regressions for each reference group and not differentiated to sex). Moreover, both studies as well as Clark and Senik (2010) find negative correlations between perceived importance of social reference groups per se and life satisfaction. ${ }^{3}$

A limitation of these three studies is that their results may only be representative for an individualistic culture like those of Germany and many other European countries (in the European Social Survey used by Clark and Senik, 2010), but less so for collectivistic (sub)cultures. For collectivistic cultures it has been found (Chung and Mallery, 1999/2000; White and Lehman, 2005) that people in such a culture are more strongly motivated to engage in upward social comparison so as to improve themselves than people in an individualistic culture. In particular, when people in a collectivistic culture form an ethnic minority in a country they may be stimulated to compare themselves upwardly to another social group with a higher socio-economic status (e.g., the ethnic majority). For example, Gokdemir and Dumludag $(2010,2011)$ have found that Turkish immigrants in the Netherlands, who are likely to form a collectivistic subculture according to the individualism-

\footnotetext{
${ }^{1}$ Relative income effects are likely to be driven by social (and economic) interactions other than social comparison as well (Frank, 2008; Vendrik and Woltjer, 2007). Typically, the means of income in the hypothetical reference groups have been adopted as proxies for the relevant incomes in these reference groups.

${ }^{2}$ In another line of research, Card et al. (2012), Carter and McBride (2013), and Montizaan and Vendrik (2014) use natural or laboratory experiments to identify social reference groups and relative-income effects on (job) satisfaction.

${ }^{3}$ These negative correlations are consistent with findings in psychology which show that people who often engage in social comparison tend to be less happy than people who do not (see, e.g., the study of Schwartz et al., 2002, about the happiness of maximizers versus satisficers).
} 
collectivism measure of Hofstede (1984) ${ }^{4}$, are much more inclined to compare themselves with Dutch natives (68\%) than Moroccan immigrants in the Netherlands (14\%), who have a more individualistic culture..$^{5}$ Thus, comparison with Dutch natives may be important for Turkish immigrants as a motivation to improve themselves (for the sake of the group). Moreover, as a result of the stimulating emancipatory effect of this comparison, the perceived importance of it may have a positive rather than negative effect on the life satisfaction of the Turkish immigrants. Another possible implication of their collectivistic culture may be the importance of comparison with relatives as an expression of feelings of connectedness with them. ${ }^{6}$ Such importance may have positive life satisfaction effects as well while having a higher income than one's relatives may have ambiguous effects.

In this study we investigate these hypotheses for a representative sample of 1005 Turkish immigrants in the Netherlands. The data for this sample was mainly collected by the first and second authors of this paper in a survey that was held in the Turkish consulate in Rotterdam, which is visited by Turkish immigrants from all layers of their population in the Netherlands to obtain necessary documents for various purposes. In this survey, besides questions about demographic and socioeconomic characteristics of the respondents, questions were asked about their levels of life satisfaction at the time of the interview and five years ago, the perceived importance of income comparison with several ethnic groups (Dutch natives, Turkish immigrants, other immigrants, people in Turkey) and life-domain groups (colleagues, neighbors, relatives in the Netherlands, relatives in other EU countries, relatives in Turkey), and the perceived levels of household income relative to these reference groups. Furthermore, the respondents were questioned about their standard of living compared to that of their parents when they were of the respondent's age and about the ethnic groups that they identified with. This yielded rich data which was employed in a regression model for current life satisfaction in terms of perceived comparison importance and relative income variables, interactions of them, and a large set of control variables. The comparison importance and relative income variables were alternatively defined as dummy or cardinal $^{7}$ variables and the control variables included the perceived level of life satisfaction of five years ago to control for unobserved timeinvariant heterogeneity of the respondents' life satisfaction levels. The model was estimated with

\footnotetext{
${ }^{4}$ The Turkish society scores low on this measure (37; Hofstede, 1984), indicating that it is collectivistic.

${ }^{5}$ The Moroccan society scores higher (46) on the individualism-collectivism scale of Hofstede(1984), indicating a more individualistic culture. Accordingly, Phalet and Schönpflug (2001) report that collectivistic values are more important in Turkish families than in Moroccan families in the Netherlands. The large difference in inclination towards comparison with Dutch natives between Turkish and Moroccan immigrants in the Netherlands cannot be attributed to differences in immigrant status as these two ethnic minorities have a similar migration history. Accordingly, White and Lehman (2005) find that the stronger inclination towards upward social comparison of Asian Canadians as compared to European Canadians is not accounted for by immigrant status.

${ }^{6}$ This interpretation is consistent with the experience of the interviewers that many respondents only understood the questions on comparison with reference groups when it was explained to them in terms of following such reference groups. This lack of understanding of the competitive concept of comparison may be due to the cooperative collectivistic nature of the Turkish culture.

${ }^{7}$ Goerke and Pannenberg (2013) call these variables ordinal, but we prefer the term "cardinal" as these variables are used as cardinal variables in our regression estimations (as well as in those of Goerke and Pannenberg).
} 
ordinary least squares and White-heteroscedasticity-consistent standard errors for all ethnic reference groups jointly and for all life-domain reference groups jointly.

The main results are as follows. For the ethnic reference groups only income comparison with Dutch natives and other (non-Turkish) immigrants turns out to have significant effects ${ }^{8}$ on the life satisfaction of the Turkish immigrants. Perceived importance of income comparison with Dutch natives has the hypothesized significant positive effect, which supports the interpretation of this comparison as a positive emancipatory stimulus in the pursuit of self-improvement of the Turkish immigrants. On the other hand, perceiving to have a lower household income than Dutch natives has a strong and significant negative effect on life satisfaction. Perceived high importance of income comparison with other immigrants has the expected negative effect on the life satisfaction of Turkish immigrants unless the respondent perceives to have a higher household income than other immigrants. In the latter case, a significant positive interaction term makes the total life satisfaction effect of perceived importance of income comparison with other immigrants insignificant. It also makes the life satisfaction effect of a higher income than other immigrants positive when income comparison with other immigrants is considered as very important. Thus, there seems to be a kind of socio-economic hierarchy with opposite life satisfaction effects of upward social comparison with Dutch natives and downward social comparison with other immigrant groups. ${ }^{9}$

For the life-domain reference groups, there are several interesting effects. Strikingly in view of the previous studies cited, the negative effect of perceiving a lower household income than colleagues is insignificant while a lower household income than neighbors significantly lowers the life satisfaction of Turkish immigrants. Perceived high importance of income comparison with relatives in the Netherlands has the hypothesized significant positive effect on life satisfaction, which can be associated with an underlying feeling of connectedness with one's relatives. On the other hand, Turkish immigrants who have a higher household income than relatives in the Netherlands are significantly less satisfied with their life, which may be interpreted in terms of the collectivistic culture of the Turkish immigrants making it unattractive to deviate too much from one's relatives (inequality aversion, cf. Fehr and Schmidt, 1999). Importance of income comparison with relatives in other EU countries (Belgium, Germany, etc.) has two opposite effects. On the one hand, finding it rather important to compare one's income with these relatives makes Turkish immigrants more satisfied with their life (relative to those for which this comparison is not important), which may again be associated with an underlying feeling of connectedness with one's relatives. On the other hand, finding it very important to compare one's income with relatives in other EU countries lowers the life satisfaction of Turkish immigrants relative to those for which this comparison is rather important. In this case, a more

\footnotetext{
${ }^{8}$ We often use the term "effect" when in fact we only found correlations. Thus, we implicitly assume that spurious correlations are sufficiently controlled for by the perceived level of life satisfaction five years ago and that causality runs from the importance and relative income variables towards life satisfaction. Section 5 contains an analysis of the causality issue.

${ }^{9}$ In this context it is interesting to note that Gokdemir and Dumludag (2010) have found in their interviews with Turkish immigrants that these immigrants are inclined to feel themselves superior in terms of socio-economic status to other immigrant groups in the Netherlands like Moroccans.
} 
individualistic and competitive attitude seems to prevail. Finally, perceived importance of income comparison with relatives in Turkey renders Turkish immigrants significantly less satisfied with life.

Our results are also relevant for the literature on migration. As is well-known, the expectations of immigrants to succeed economically in the new country is an important motive to immigrate. However, after immigration income levels of immigrants usually remain lower than those of native people, and immigrants tend to report lower levels of life satisfaction than natives (Verkuyten, 1986, 2008; Cornelisse-Vermaat, 2005; Safi, 2010). Bartram (2010) states that migration leading to settlement raises the question to which reference groups immigrants compare themselves. Immigrants can continue to compare themselves to those who still live in the country of origin, but they can also create new reference groups of other people (such as natives) in the destination country. Our study sheds light on this issue by showing that for Turkish immigrants in the Netherlands Dutch natives form an important reference group, but that the negative life satisfaction effect of a lower relative income is compensated by a positive stimulating effect of finding it very important to compare one's income with them. ${ }^{10}$ Moreover, we also consider other reference groups like Turkish and other immigrants in the Netherlands and relatives, and find that attaching a high importance to income comparisons with other immigrants and relatives in other EU countries and Turkey lowers the life satisfaction of Turkish immigrants while finding it very important to compare one's income with relatives in the Netherlands has a positive impact on the immigrants' life satisfaction.

The organization of this paper is as follows. First, Section 2 describes the survey and the data extracted from that, presents descriptive statistics of the reference group variables, and discusses the control variables and the representativeness of the sample. Then, Section 3 explains the regression model, hypotheses and estimation method. The results from estimating this model are presented and analysed in Section 4. Section 5 presents robustness estimations and discusses the causality issue, and Section 6 concludes.

\section{Data, descriptive evidence, and variables}

\subsection{Survey}

The survey consists of data entries from 1005 respondents. They come from two subsamples, namely a subsample based on face-to-face interviews at the Turkish consulate in Rotterdam with country-wide representative sampling of 858 respondents from various regions in the Netherlands ${ }^{11}$ and a random subsample (as control group) with 148 respondents who filled in the survey through internet. ${ }^{12}$ The

\footnotetext{
${ }^{10}$ This finding can also be related to the analysis in Leites (2015) that connects the literature on intergenerational income mobility to the effects of income comparison with various social reference groups on satisfaction with economic conditions and following behaviour.

${ }^{11}$ At the time of the field study 320.000 Turkish immigrants ( 82 percent of the total population of Turkish immigrants in the Netherlands) from various regions in the Netherlands were registered at the Turkish Consulate in Rotterdam.

${ }^{12}$ Names of people for this subsample were randomly selected from a wide pool based on information from municipality records, a non-governmental organizations database, databases of social networks, etc. Moreover,
} 
data covers 629 men and 375 women of Turkish national origin. ${ }^{13}$ However, the regression analyses presented in the paper had to use a lower number of observations due to missing values for at least one of the variables of interest. The survey was designed during the first half of 2012 and was implemented between September 2012 and June 2013. ${ }^{14}$ The interviews in the Turkish consulate lasted approximately 30 minutes, and there was no show-up fee paid. The non-response rate of people approached was $20 \%$ (of which 10\% refusals) in the consulate subsample and between 25 and $30 \%$ in the internet subsample. ${ }^{15}$ We designed the survey with over 30 questions concerning (i) life and income satisfaction, (ii) perceived importance of income comparison with several social reference groups and perceived household incomes relative to them, and (iii) a wide range of demographic, socio-economic, and socio-cultural background variables such as gender, age, marital status, educational level, labour force status, religion, identity, and social belonging.

\subsection{Descriptive evidence on income comparison}

A key comparative advantage of our data is that it provides direct information on the intensity of income comparisons and perceived relative income of respondents with respect to an exogenously given set of nine reference groups composed of four ethnic and five life-domain groups. The ethnic reference groups were Dutch natives, other Turkish immigrants in the Netherlands, other (nonTurkish) immigrants in the Netherlands, and Turkish people in Turkey. The life-domain reference groups were colleagues, neighbors, relatives living in the Netherlands, relatives living in other EU countries (Belgium, Germany, etc.), and relatives living in Turkey. Separate questions were asked for the two subsets of ethnic and life-domain reference groups. ${ }^{16}$ In the first question for each subset, respondents were requested to indicate the importance of income comparisons with the four or five reference group on a 1-3 scale ranging from "completely unimportant" to "very important". The second question asked respondents to report how their household income compared with those groups on a 1-5 scale ranging from "much lower" to "much higher". The percentages of the scores for these questions among the respondents are indicated in Tables 1 and 2.

Insert Table 1 here

about 35 people were approached on streets in Rotterdam, Arnhem, Maastricht, and Den Haag to fill in the questionnaire.

${ }_{13}^{13}$ One respondent did not declare his/her sex.

${ }^{14}$ The survey interviews were held in Turkish by the first and second authors of this paper at the waiting room of the Turkish consulate at Rotterdam. The waiting room is at the ground floor and has no direct connection with the service points which are located on the first and second floors (except for an information desk). In the waiting room there are chairs for 80 people plus a very small playground for children. The waiting room also serves as a social meeting point for the immigrants from Turkey.

${ }^{15}$ The non-response rate in the internet subsample could not be determined exactly as some respondents may have forwarded the link to the questionnaire to relatives or friends.

${ }^{16}$ See Appendix A for the English translations of these Turkish survey questions. 
Table 1 for the ethnic reference groups shows that about 80 percent of the respondents find it important (rather or very) to compare their household income with Dutch people and with their own group of Turkish immigrants in the Netherlands, and even more so (84\%) with people in Turkey. On the other hand, 88 percent does not attach much importance to income comparison with other immigrants in the Netherlands. The high perceived importance of income comparison with Dutch natives is remarkable in view of the fact that half of the respondents perceive their household income as lower or much lower than that ${ }^{17}$ of Dutch natives. On the other hand, many respondents view their household income as higher or much higher than those of people from their own group of Turkish immigrants, other immigrants, and people in Turkey.

\section{Insert Table 2 here}

For the life-domain reference groups, Table 2 shows that about 75 percent of the respondents find it important (rather or very) to compare their household income with colleagues and with relatives in the Netherlands, and even more so $(80 \%)$ with relatives in Turkey. On the other hand, more than 80 percent does not attach much importance to income comparison with neighbors and to income comparison with relatives in other EU countries. Regarding perceived relative incomes, more than $20 \%$ see their household incomes as higher or much higher than those of colleagues and relatives in the Netherlands and other EU countries, and not surprisingly, more than 55\% as higher or much higher in comparison to relatives in Turkey. On the other hand, more than $40 \%$ of the respondents perceive their household income as lower than that of relatives in other EU countries, and more than $60 \%$ see their household income as similar to that of neighbors.

An important question is whether the perceived importance of income comparison data in our survey taps dimensions of income comparison that are essentially different from those elicited from the perceived relative income data. For example, respondents who perceive to have a higher or lower household income than a certain reference group may be more inclined to state that income comparison with that reference group is important than those with a perceived similar relative income (Goerke and Pannenberg, 2013). To answer this question, we regressed the perceived importance of income comparison variables for the various reference groups on the relative income variables and all other key and control variables (but separately for the two subsets of ethnic and life domain reference groups, see Section 3). These regressions did not reveal (marginally) significant correlations between income comparison importance and relative income variables for the same reference group except for comparison with other Turkish immigrants, which however turned out not to have significant effects in the life satisfaction regressions (see Section 4). On the other hand, the importance variables strongly positively correlate with all or almost all other (ethnic or life-domain) importance variables, thus indicating an overall tendency of respondents to attach more or less importance to income

\footnotetext{
${ }^{17}$ Probably, respondents have a kind of perceived average level of household income of Dutch natives they know in their mind when answering this question.
} 
comparisons with groups of other people. This is consistent with the suggestion from findings in psychology that the propensity to engage more or less frequently in social comparison is a personspecific trait (see, e.g., Schwartz et al., 2002).

\subsection{Other variables}

The dependent variable in the regression model in this study is life satisfaction, which is composed of individual responses to the question: All things considered, how satisfied are you with your life as a whole these days? Respondents were asked to indicate a score on an ordinal scale ranging from 0 (completely dissatisfied) to 10 (completely satisfied). In the survey we also asked for the respondents' level of life satisfaction of five years ago. Answers to these questions are based on respondents' selfassessments and are well-known as measures of subjective well-being. Descriptive statistics for these variables and the variables explained below are given in Table B.1 in Appendix B. ${ }^{18}$

Apart from the main explanatory variables, we control for household income, comparison of the standard of living with parents, and demographic, socio-economic and socio-cultural variables. The question on household income was presented in ten income brackets of mean net household income of several ethnic minority groups in the Netherlands, and respondents were asked to indicate in which income range their household income fell. The income brackets ranged from below 1500 euros monthly for the lowest category to above 5500 euros monthly for the highest category. The question on the comparison of the standard of living with that of the parents was presented with a 1-5 answer scale from "much worse" to "much better".

The demographic questions concerned a large set of control variables such as gender, age, generation, household size, number of children, and marital status. The dummy variable gender equals one if the respondent is male and zero if the respondent is female. The variable age represents the respondent's age in years. Since previous studies have found a quadratic relationship between age and happiness, we also use age squared as a control variable. Moreover, we use a control variable which distinguishes between five subcategories of the sample as first, 1.5, second, 2.5, and third generations to make meaningful comparisons between the different cohorts. The first generation consists of people who were born in Turkey and who came to the Netherlands after age 11, and the 1.5 generation of those born in Turkey who came to the Netherlands before age 12. The second generation consists of people born in the Netherlands with both parents born in Turkey, and the 2.5 generation of those born in the Netherlands with one parent born in Turkey and one parent born in the Netherlands. People of the third generation were born in the Netherlands and their parents were also born in the Netherlands. The 1.5 generation is the largest group of people in the survey ( 49 percent).

The variable household size represents the number of people living in the house in which the respondent lives. "Number of children" indicates the number of children of the respondent. Four

\footnotetext{
${ }^{18}$ It is interesting to note that for life satisfaction in the Turkish consulate subsample there are two local maxima in the life satisfaction distribution among the respondents: a higher peak at 8 and a lower peak at 5 . This deviates from the overall life satisfaction distribution in the Dutch population which tends to have one peak at 8 .
} 
dummy variables indicate marital status: "married" equals one if the respondent is married and zero otherwise; "widowed" equals one for respondents who have been widowed, and equals zero otherwise; "separated/divorced" equals one for respondents who are separated or divorced and zero otherwise; "single" equals one for respondents who are living alone and zero otherwise. The omitted reference case for marital status is "married". ${ }^{19}$

The socio-economic variables represent educational level and labour force status. We distinguish six different educational categories. The first category consists of individuals with no or an elementary school degree. The second category has a secondary school degree. The third category has a high school degree. The fourth category has a vocational school degree. The fifth and sixth categories have undergraduate and postgraduate degrees, respectively. Labour force status is indicated by six additional zero/one dummies: "full-time", "part-time", "self-employed", "retired", "housewife", "student", and "non-working". The omitted reference category is "full-time".

The socio-cultural variables concern religion and identity. Respondents' ratings of the importance of religion in their lives on an integer scale of 1 (least important) to 5 (most important) are recorded in the variable religion. The identity variables consist of several identities that respondents may feel closely connected to. The dummy variables in this category are Turkish, Muslim, Dutch citizen, European Union citizen, World citizen, and other identity. These dummy variables equal one if the respondent selects the pertinent identity and zero otherwise. The omitted reference category is Turkish identity.

\subsection{Representativeness of the sample}

In order to investigate the representativeness of our sample, we compare the descriptive statistics of most control variables with those of a representative subsample of Dutch inhabitants with a Turkish nationality between age 16-75 from the Dutch Labour Force Survey (EBB) ${ }^{20}$ Table B.1 in Appendix B shows that about half of the means statistics of the two samples are reasonably close to each other with the notable exceptions of those for gender, elementary, secondary, high-school and undergraduate education, full-time working, self-employed and non-working. ${ }^{21}$ Men, immigrants with high-school and undergraduate degrees, and full-time and self-employed immigrants are overrepresented in our sample whereas women, immigrants with only elementary and only secondary education and nonworking $^{22}$ immigrants are underrepresented. This may be attributed to female, lower-educated, and non-working immigrants not coming as easily to the Turkish consulate as male, higher-educated, and working immigrants. It is also possible that some respondents indicated a high-school or

\footnotetext{
${ }^{19}$ The questionnaire also includes a question on subjective health. However, we do not control for this variable in our estimations as it is likely to be endogenous to life satisfaction, and hence to lead to downward biases in the sizes of the other coefficient estimates.

${ }^{20}$ We thank Ineke Bijlsma for kindly providing us with the descriptive statistics of the latter subsample.

${ }^{21}$ The means of these variables in the two samples are significantly different from each other according to a ttest. The means for generation are not fully comparable as the EBB does not distinguish 1.5 and 2.5 generations.

${ }^{22}$ The non-working percentage of $40 \%$ in the EBB should be compared with the sum of non-working, retired and housewife percentages of $23 \%$ in our sample.
} 
undergraduate education in their interviews while not having completed such an education (as asked for in the pertinent question). Thus, the representativeness of our sample is limited, but in our view still reasonably good.

\section{Model and hypotheses}

In its most general form, the baseline cross-section model that we employ is specified as follows:

$$
S_{i}=\alpha+\sum_{j=1}^{m}\left(\beta_{j} I_{i}^{R j}+\boldsymbol{\gamma}_{j} \boldsymbol{Y}_{i}^{R j}+\boldsymbol{\delta}_{j} I_{i}^{R j} \boldsymbol{Y}_{i}^{R j}\right)+\kappa \ln Y_{i}+\sum_{k=1}^{p} \lambda_{k} X_{i}^{k}+e_{i}
$$

where $S_{i}$ is the life satisfaction of respondent $i, I_{i}^{R j}$ is a measure of the perceived importance of the incomes of reference group $j, \boldsymbol{Y}_{i}^{R j}$ is a vector or scalar measure of the perceived household income relative to reference group $j, Y_{i}$ is household income, $X_{i}^{k}, k=1, \ldots, p$, represent other controls, the Greek symbols indicate parameters, and $e_{i}$ is an idiosyncratic error. The interaction terms of perceived importance and relative income $\boldsymbol{Y}_{i}^{R j}$ are included in the model as it may be expected that the weight of household income relative to a certain reference group in a person's life satisfaction is positively related to the importance the person attaches to the incomes in that reference group. With respect to the set of reference groups that are incorporated in model (1), there are two variants: one with reference groups of Dutch natives, other Turkish immigrants in the Netherlands, other immigrants in the Netherlands, and Turkish people in Turkey, and another one with reference groups of colleagues, neighbours, relatives living in the Netherlands, relatives in other EU countries, and relatives in Turkey. We refer to the former set of reference groups as the ethnic reference groups and to the latter set as the life-domain reference groups. These two sets of reference groups are not combined into one large set of reference groups as the reference groups in one set may overlap too much with reference groups in the other set, and hence may give rise to problems of multicollinearity.

The controls $X_{i}^{k}$ include gender, age, age squared, generation, remembered life satisfaction of five years ago, dummies for marital status, numbers of children and adults in the household, dummies for level of education, labour force status, and perceived identity, religion, and standard of living compared to that of the parents when they were of the respondent's age (better or worse) (see the descriptive statistics Table B.1 for a full list of all control variables used in the estimations). The level of life satisfaction of five years ago as remembered by the respondent is assumed to control for spurious correlations between reference group variables and life satisfaction via time-invariant omitted variables like personality characteristics. Perceived identity variables are included as otherwise their effects may be picked up by the key variables of perceived importance of the reference groups. Standard of living compared to that of parents represents the intergenerational influence of household income relative to the reference group of parents. 
In estimating model (1), two sets of measures of the perceived importance $I_{i}^{R j}$ of reference group $j$ and perceived relative income $\boldsymbol{Y}_{i}^{R j}$ are used. The first set consists of one dummy variable for $I_{i}^{R j}$ and two dummy variables for $\boldsymbol{Y}_{i}^{R j}$. The dummy for importance equals one when the answer to the pertinent survey question (see Section 2) is "very important", and zero otherwise. It is defined like this as estimations of equation (1) with two dummy variables for the answers "very important" and "completely unimportant" (with "rather important" as the omitted reference case) revealed that for many reference groups the life satisfaction effects of differences in the perceived importance variables between "rather important" and "very important" are (marginally) significant whereas for almost all reference groups the life satisfaction effects of differences between "completely unimportant" and "rather important" are (marginally) insignificant. The two dummies for relative income are defined as being equal to one when the answer to the corresponding survey question is "much lower" or "lower", respectively "higher" or "much higher". The second set of measures consists of two cardinal variables. The cardinal variable for importance is coded as 1 for the answer "completely unimportant" to the pertinent question, 2 for "rather important", and 3 for "very important". The cardinal variable for relative income is defined as the natural logarithm of 1 for the answer "much lower", 2 for "lower", 3 for "about the same", 4 for "higher", and 5 for "much higher". The logarithmic form is chosen to reflect the stronger life satisfaction effects of lower as compared to higher relative income as found for most reference groups in the estimations of equation (1) with the dummy specifications of the comparison variables.

On the basis of previous literature on effects of perceived importance of reference groups on subjective well-being (Mayraz et al., 2009; Clark and Senik, 2010; Goerke and Pannenberg, 2013), we expect negative signs of the estimates of the coefficients $\beta_{j}$ of $I_{i}^{R j}$ in equation (1) for most reference groups. Thus, respondents may tend to be less satisfied with their life when comparing with others is more important for them. However, income comparison with Dutch natives, which has been found to be important for Turkish immigrants by Gokdemir and Dumludag (2011), may also have a positive effect on their life satisfaction by stimulating self-improvement. Such motivation seems especially strong in collectivistic cultures (Chung and Mallery, 1999/2000; White and Lehman, 2005), one of which is the Turkish culture. Moreover, in such cultures importance of income comparison with relatives may also have a positive effect on life satisfaction as an expression of feelings of connectedness with one's relatives.

Perceived household income relative to important reference groups $\left(\boldsymbol{Y}_{i}^{R j}\right)$ is, in general, expected to have a positive effect $\left(\gamma_{j}\right)$ on life satisfaction when it is higher than the household income of the reference group and a negative effect when it is lower. However, in a collectivistic culture like the Turkish, having a higher household income than one's relatives may have ambiguous effects on life satisfaction. Regarding the interaction terms, their insignificance in studies by Mayraz et al. (2009) and Goerke and Pannenberg (2013) for German data suggests that they will be insignificant in our estimations as well despite their a priori plausibility. If interaction terms are indeed separately and 
jointly insignificant, they are dropped from model (1) in subsequent estimations in order to enhance statistical power. Furthermore, to increase consistency between the results for the dummy and cardinal model variants the cardinal linear and logarithmic specifications are replaced by quadratric or quartic specifications for some particular reference group variables.

For the control variables we expect the usual signs found in the happiness literature. In particular, it is anticipated that the standard of living compared to that of the parents will have a positive effect if it is higher and a negative effect if it is lower. Because we control for many relative income components, coefficient $\kappa$ of $\ln Y_{i}$ will capture the absolute income effect, which is expected to be zero or even negative in view of the results of Gokdemir and Dumludag (2011). ${ }^{23}$ The signs of the coefficients of the identity variables are anticipated to be non-zero and those of the other control variables are expected to be in line with the estimates in Gokdemir and Dumludag (2011) and other happiness studies for immigrants.

We estimate our cross-section model using ordinary least squares (OLS) regressions, which treat life satisfaction as a cardinal construct. We use this type of model as the results of cardinal models are more intuitive and easier to interpret than estimates from ordinal probit models. In addition, cardinal and ordinal analyses of life satisfaction yield, in general, similar results (Ferrer-iCarbonell and Frijters, 2004). ${ }^{24}$ Standard errors of the coefficient estimates are White heteroscedasticity-consistent as heteroscedasticity tests reject homoscedasticity of the residuals.

\section{Estimation results}

In this section we present four groups of estimations for two by two combinations of the ethnic and life-domain sets of reference groups on the one hand, and the dummy and cardinal specifications of the reference group variables on the other hand. For both the ethnic and life-domain reference groups, first the estimates for the dummy specifications are discussed as these seem more reliable than the rather restrictive cardinal estimates, and then the latter estimates are presented and compared with the former estimates.

\subsection{Ethnic reference groups}

For the ethnic reference groups and the dummy specifications, estimating equation (1) yielded interaction coefficients that were all insignificant, but three of them were "weakly" insignificant $(p<$

\footnotetext{
${ }^{23}$ In this study the coefficients of the income and social comparison variables are misinterpreted as absolute and relative income effects, respectively. The social-comparison variable is a proxy for the average household income and social status in the various social reference groups of the Turkish immigrants rather than a relative income variable. Consequently, the coefficient of the income bracket variable represents an ordinary income effect at given social reference income (see Vendrik, 2013, for the distinction between the various income effects). The estimate of this income effect for Turkish immigrants is insignificantly negative in the study of Gokdemir and Dumludag (2011), while the unidentified absolute income effect could be expected to be even more negative (cf. Vendrik, 2013).

${ }^{24}$ Goerke and Pannenberg (2013) also obtain results with a rating scale model that are very similar to their OLS estimates.
} 
0.16). To get easily interpretable estimates of the main effects and to gain statistical power, we dropped the other, separately and jointly insignificant interaction terms. This left us with one significant interaction term for high importance of comparing one's household income with those of other immigrants and having a higher household income than other immigrants while the other two interaction terms were insignificant $\left(p=0.16\right.$ and 0.24 ). Dropping the latter two interaction term ${ }^{25}$ one by one preserved the significance of the remaining interaction term and resulted in coefficients of the reference group variables that were all separately and jointly insignificant for the reference groups of other Turkish immigrants in the Netherlands and Turkish people in Turkey. Table 3 therefore only presents the estimates for the reference groups of Dutch natives and the other immigrants (see Appendix $\mathrm{C}$ for the full estimation results).

\section{Insert Table 3 here}

Attaching a high importance to income comparison with Dutch natives and perceiving to have a lower household income than Dutch natives both have (marginally) significant and sizable effects on the life satisfaction of Turkish immigrants. This is in line with the finding of social comparison with Dutch natives by Gokdemir and Dumludag (2011). The effect of a lower household income than Dutch natives has the expected negative sign, but the positive sign of the effect of high importance of income comparison with Dutch natives deviates from the negative effects of perceived importance of reference groups that are generally found in other studies (Mayraz et al., 2009; Clark and Senik, 2010; Goerke and Pannenberg, 2013). The positive importance effect can be interpreted as being the result of the collectivistic culture of the Turkish immigrants in which they are stimulated to engage in upward social comparison with other social groups with a higher socio-economic status so as to improve themselves (Chung and Mallery, 1999/2000; White and Lehman, 2005). Our finding of a positive importance effect suggests that such motivation considerably raises the life satisfaction of the Turkish immigrants. On the other hand, when they perceive their household income as being lower than that of Dutch natives, their life satisfaction is suppressed by an even higher amount. The total sum of these two effects for those who find it very important to compare their household income with those of Dutch natives, but perceive to have a lower income is negative, but insignificant (see second panel of Table 3). Thus, for these individuals the two effects compensate each other so as to make the total life satisfaction effect of comparing their incomes with those of Dutch natives insignificant.

The life satisfaction effect of a higher household income than Dutch natives is insignificant, which is in line with studies that find an insignificant happiness effect of downward (as opposed to upward) social comparison. However, when Turkish people with a higher household income than Dutch natives find it very important to compare with them, the total sum of the two effects is strongly positive and significant (second panel of Table 3). Thus, the total life satisfaction effect of finding it

\footnotetext{
${ }^{25} \mathrm{~A} F$ test for the full regression with all interaction terms revealed that the dropped interaction terms are jointly insignificant.
} 
very important to compare one's income with those of Dutch natives and having a household income higher than or similar to those of Dutch natives is considerably positive. Hence, our estimates suggest that Turkish immigrants who find it very important to compare their income with Dutch natives are substantially more satisfied with life than other Turkish immigrants unless they perceive to have a lower household income than Dutch natives.

Finding it very important to compare one's income with other immigrants ${ }^{26}$ also has a significant effect on life satisfaction, but now the effect is negative. However, perceiving to have a lower or higher household income than other immigrants does not have significant effects on life satisfaction. The total effect of a high importance of income comparison with other immigrants and a lower household income than them is almost marginally significant $(p=0.11$; second panel of Table 3). On the other hand, for those who find it very important to compare their income with other immigrants and perceive to have a higher household income than them there is a significant and large positive interaction effect. This interaction effect is in line with our expectation stated in Section 3 that the weight of household income relative to a certain reference income in a person's life satisfaction is positively related to the importance the person attaches to that reference group. It makes the life satisfaction effect of a higher household income than other immigrants significant and positive when a high importance is attached to income comparison with other immigrants (see second panel of Table 3 for this and further derived effects). It also makes the life satisfaction effect of high importance of income comparison with other immigrants strongly insignificant for those with a higher household income than other immigrants (two counteracting effects). As a result, the total life satisfaction effect of high importance of income comparison with other immigrants and a higher household income than them (sum of three effects) is strongly insignificant as well. Thus, Turkish people who find it very important to compare their income with other immigrants are much less satisfied with life than other Turkish people unless they perceive to have a higher household income than other immigrants. In the latter case there is also a strong positive effect of downward social comparison with other immigrants on the life satisfaction of these Turkish people, which compensates for the negative effect of attaching a high importance to income comparison with other immigrants per se. Thus, while there is a strong negative effect of a lower household income than Dutch natives, there is a strong positive effect of a higher income than other-than-Turkish immigrants. This suggests a kind of socio-economic hierarchy with opposite life satisfaction effects of upward social comparison with Dutch natives and downward social comparison with other immigrant groups.

A complication in the interpretation of the main life satisfaction effects of high importance of income comparison with other immigrants and a higher income than them is that they represent the main effects when the interaction term is zero, so when the Turkish respondents perceive their income to be similar to or lower than those of other immigrants and attach a moderate or no importance to the income comparison with them, respectively. For comparison of the main effects with those of income

\footnotetext{
${ }^{26}$ Note from Table 1 that this only holds for $12.3 \%$ of the total sample of 913 respondents, so for 112 of them.
} 
comparison with other reference groups and the estimates in the literature, it would be useful to estimate the mean main effects of the income comparison with other immigrants for the whole sample. This can be done by re-estimating the regression of Table 3 with the interaction term specified in terms of deviation of the importance and relative income dummies from their sample means $(0.123$ for the importance dummy and 0.356 for the relative income dummy). This yields a mean main effect estimate of high importance of income comparison with other immigrants of $-0.421 \pm 0.243$, which is marginally significant $(\mathrm{p}=0.08)$, and an insignificant mean main effect estimate of a higher income than other immigrants of $0.036 \pm 0.163$. The former estimate is comparable in size to the coefficient of high importance of income comparison with Dutch natives and its negative sign is in accordance with that found in the studies cited above.

In addition to the key reference group coefficients, Table 3 also presents the coefficient estimates for worse or better living standard than the parents and $\ln$ income. Both former coefficients are strongly significant and large, which indicates the importance of intergenerational comparison with the living standard of the parents. As expected, the negative effect of a worse living standard is stronger in size than the positive effect of a better living standard. The coefficient of $\ln$ household income, which represents the absolute income effect at constant values of the relative income variables, is strongly insignificant, which was expected as well in view of the results of Gokdemir and Dumludag (2011).

Estimating equation (1) in the cardinal specification again yielded insignificant interaction terms with the interaction term for importance of comparing one's income with other migrants and $\mathrm{ln}$ household income in comparison to migrants again being "weakly" insignificant $(p=0.12)$. Dropping the other, separately and jointly insignificant interaction terms resulted in coefficients of the reference group variables that were only significant for Dutch natives. To improve consistency of these cardinal estimates with the significant coefficients of high importance of income comparison with other immigrants and its interaction term with higher household income than other immigrants that were found for the dummy specification in Table 3, we replaced the linear term in importance of income comparison with other immigrants by a quartic term in both the main and interaction terms. Table 4 shows that this yielded a marginally significant $(p=0.07)$ coefficient of quartic importance of income comparison with other immigrants and an almost marginally significant $(p=0.12)$ coefficient of the interaction term of quartic importance and $\mathrm{ln}$ relative income (see Appendix $\mathrm{C}$ for the estimation results for all social comparison variables). These more significant results for the quartic as compared to the linear specification of the cardinal importance terms for other immigrants reflect the extremely concave shape of the relationship between life satisfaction and the scores 1,2 and 3 for importance of income comparison with other immigrants. ${ }^{27}$ Whereas there is a strong negative life satisfaction effect

\footnotetext{
${ }^{27}$ The coefficient of the interaction term becomes less insignificant as we raise the power of the importance term and even becomes marginally significant $(\mathrm{p}=0.09)$ for power 8 . However, for the sake of presentation, Table 2 presents the results for the power 4 as the pertinent coefficients then are less small.
} 
of an increase in the score from 2 (= rather important) to 3 (= very important), the effect of an increase from 1 (= completely unimportant) to 2 is negligible. ${ }^{28}$

\section{Insert Table 4 here}

The life satisfaction effects of importance of income comparison with Dutch natives and household income relative to Dutch natives are significant, positive and sizable in line with the results for the dummy specification in Table 3. Especially the ln relative income effect is remarkable large in comparison with relative income effects found in the literature (e.g., Vendrik, 2013). The ln specification is consistent with the asymmetry in the lower and higher-income effects in Table 3 by virtue of its diminishing-marginal-utility property. In this cardinal case we do not present derived effects as they are more difficult to construct and interpret than those for the dummy specification in Table 3, and do not add much to the latter derived effects. The coefficients of worse and better living standard than one's parents and ln household income are similar to those in Table 3.

\subsection{Life-domain reference groups}

For the life-domain reference groups and the dummy specification, estimating equation (1) yielded one marginally significant and two "weakly" insignificant $(p<0.15)$ interaction terms. Dropping the other, separately and jointly insignificant interaction terms in the estimation, two of the remaining interaction terms became marginally significant while the third one became insignificant. Dropping the last interaction term made one of the other two insignificant $(\mathrm{p}=0.16)$, which was then dropped as well. This resulted in the remaining interaction term becoming also insignificant ( $p=0.18)$, so we dropped that as well and checked that all interaction terms in the full specification are jointly insignificant $(\mathrm{p}=$ 0.18). From the resulting coefficient estimates Table 5 only presents the significant, (almost) marginally significant and related ones (see Appendix $\mathrm{C}$ for the estimation results for all social comparison variables). ${ }^{29}$

\section{Insert Table 5 here}

For the reference group of colleagues, which has been found to be important in several other studies (e.g., Mayraz et al., 2009; Clark and Senik, 2010; Goerke and Pannenberg, 2013), we do not find significant effects. On the other hand, for the reference group of neighbours, which has been found to be less important or to give even rise to negative relative income effects (in a cardinal

\footnotetext{
${ }^{28}$ We checked this in an estimation with two importance-of-comparison dummies for the answers "completely unimportant" and "very important" for each reference group.

${ }_{29}$ Our finding of two marginally significant interaction terms in one of the model selection stages suggests a more differentiated structure of life satisfaction effects than what finally emerged out of the selection. However, in this baseline analysis we prefer to present a simpler picture in which the main effects can be interpreted easily. In Section 5.2 we will offer a more differentiated structure of life satisfaction effects for the subsample of the Turkish consulate group.
} 
specification) in the studies cited, Table 5 shows a strongly significant, negative and large effect of a lower household income than neighbors. Relatives living in the Netherlands also turn out to be an important reference group. Respondents who find it very important to compare their income with them are significantly and considerably more satisfied with life than others. Moreover, and surprisingly, having a higher household income than their relatives has the opposite effect of making Turkish people marginally significantly $(\mathrm{p}=0.05)$ and substantially less happy. Both effects may be due to the collectivistic culture of the Turkish immigrants which, on the one hand, makes them more satisfied if they feel connected to their family, and hence find it very important to compare their income with close relatives, but on the other hand, makes it unattractive to deviate too much from them. As a result, the combined life satisfaction effect of finding it very important to compare one's income with relatives in the Netherlands and having a higher household income than them is insignificant (see the second panel of Table 5). However, for those who have a household income similar to or lower than relatives there is only a significant positive effect of high importance of income comparison with relatives. As suggested above, this effect may pick up an underlying positive effect on life satisfaction of connectedness with one's family. The latter effect is not controlled for by a corresponding perceived-identity variable.

Attaching a high importance to income comparison with relatives in other EU countries (Belgium, Germany, etc.) and Turkey also has marginally significant $(\mathrm{p}=0.08)$ and considerable effects on life satisfaction, but now these effects are negative in line with the negative sign of the effects found in the studies cited above. In these cases collectivism does not seem to be the dominant force. A better living standard than the parents has a less positive and only marginally significant $(\mathrm{p}=$ 0.09 ) effect on life satisfaction as compared to the effect in the regression with ethnic reference groups in Table 3.

Estimating equation (1) in the cardinal specification again yielded only one marginally significant $(\mathrm{p}=0.11)$ interaction term for importance of income comparison with neighbors and $\mathrm{ln}$ household income relative to them. Dropping the other, separately and jointly insignificant interaction terms, the remaining interaction term for neighbors became strongly insignificant as well, and as it was also jointly insignificant with the other interaction terms, we dropped it as well. This resulted in coefficient estimates that were consistent with those for the dummy specification in Table 5 except for insignificant coefficients of $\ln$ household income relative to relatives in the Netherlands and importance of income comparison with relatives in other EU countries. To improve consistency of these cardinal estimates with the (marginally) significant corresponding estimates in Table 5, we replaced $\ln$ household income relative to relatives in the Netherlands by a quadratic specification of relative income and added a quadratic term to the linear term for importance of income comparison with relatives in other EU countries. The resulting coefficient estimates that correspond to those in Table 5 are presented in Table 6 (see Appendix $\mathrm{C}$ for the estimation results for all income comparison variables). 


\section{Insert Table 6 here}

The life satisfaction effect of ln household income relative to neighbors is strongly significant, positive and large, in line with the corresponding estimate in Table 5. Importance of income comparison with relatives in the Netherlands has a marginally significant effect $(p=0.09)$ while the linear term in household income relative to these relatives has no significant coefficient and the quadratic term in relative income shows an almost marginally significant $(\mathrm{p}=0.14)$ negative coefficient. Thus, the last estimate only partially reproduces the marginally significant negative effect of higher household income than relatives in the Netherlands that was found in Table 5. On the other hand, the significant, strong and negative quadratic effect of importance of income comparison with relatives in other EU countries is fully consistent with the marginally significant, large and negative effect of high importance of that comparison in Table 5. In addition, there is a significant, strong and positive effect of importance of income comparison with relatives in other EU countries for lower degrees of that importance (completely unimportant and rather important). The coefficient estimates of the linear and quadratic terms imply that Turkish migrants who attach some importance to income comparison with relatives in other EU countries are marginally significant $(\mathrm{p}=0.09$ and 0.08 , respectively) more satisfied than those who do not attach any importance to it as well those who attach much importance to it (see second panel of Table 6 ).$^{30}$ Thus, for lower degrees of importance of income comparison with relatives in other EU countries the collectivistic positive effect of importance on life satisfaction dominates whereas for higher degrees of importance the more individualistic and competitive negative effect prevails. Finally, the significant negative effect of importance of income comparison with relatives in Turkey is consistent with the corresponding estimate in Table 5.

\section{Robustness}

In this section we investigate the robustness of our baseline results to restricting the estimations to subsamples of men, women, and the Turkish consulate group, and to dropping and adding some important control variables. We also discuss and analyse the potential problem of reverse causality from life satisfaction to the comparison importance and relative income variables.

\subsection{Subsamples of men and women}

Estimating regression equation (1) for the ethnic and life-domain reference groups and the dummy and cardinal specifications for men and women separately only yields reliable results for the ethnic reference groups for men as in the other cases the number of observations is too small as compared to the number of explanatory variables. As a criterion for this we use the statistical rule of thumb that the

\footnotetext{
${ }^{30}$ This result is also obtained in an estimation with two importance-of-income-comparison dummies for the answers "completely unimportant" and "very important" for each reference group. The difference between the life satisfaction of those who attach much importance to the income comparison with relatives in other EU countries and those who do not attach any importance to it is insignificant.
} 
number of observations should be larger than the number of explanatory variables times ten. When this criterion is violated, over-fitting may occur and estimation results are unstable, i.e. sensitive to addition or omission of observations. The criterion is especially violated for the female subsample which only counts about 280 observations being much smaller than the number of explanatory variables times ten in all regressions (larger than about 400 without insignificant interaction terms). For this subsample there are suspiciously many significant and large coefficient estimates with strange signs suggesting over-fitting. The male subsample is much larger and is just larger than the number of variables (without insignificant interaction terms) times ten in the regressions for the ethnic reference groups (469 observations against $10 \times 42=420$ variables in the dummy specification and 466 observations against $10 \times 39=390$ variables in the cardinal specification). On the other hand, the male subsample is smaller than ten times the number of variables in the regressions for the life-domain reference groups (398 observations against $10 \times 49=490$ variables in the dummy specification and against $10 \times 41=410$ variables in the cardinal specification) and yields many significant and large coefficient estimates with strange signs in the dummy specification. Therefore, we only present the coefficient estimates of the regressions for the ethnic reference groups for men in Tables 7 and 8 .

\section{Insert Table 7}

In comparison with the estimates for the full sample in Table 3, the estimates for the dummy specification for men in Table 7 again show a significant negative life satisfaction effect of perceiving to have a lower household income than Dutch natives, but, in deviation from Table 3, also show an insignificant coefficient of high importance of income comparison with Dutch natives, an only almost marginally significant $(\mathrm{p}=0.11)$ coefficient of high importance of income comparison with other immigrants, a significant coefficient of a lower household income than other immigrants, and an only almost marginally significant $(\mathrm{p}=0.14)$ interaction effect of high importance of income comparison with other immigrants and a higher household income than other immigrants. Especially, the strong insignificance of the male life satisfaction effect of attaching a high importance to income comparison with Dutch natives is remarkable. ${ }^{31}$ The total life satisfaction effect of finding it very important to compare one's income with Dutch natives and a lower perceived household income than Dutch natives is again insignificant and the total life satisfaction effect of a high importance of income comparison with Dutch natives and a higher perceived household income than Dutch natives is insignificant as well. On the other hand, the total life satisfaction effect of high importance of income comparison with other immigrants and a lower household income than them is strongly significant and negative for men. The life satisfaction effect of a higher household income than other immigrants when a high importance is attached to this comparison is almost marginally significant $(\mathrm{p}=0.14)$ and positive

\footnotetext{
${ }^{31}$ Estimations of the small female sample suggest that the significant life satisfaction effect of high importance of income comparison with the Dutch in the full sample estimation may be driven by its effect on the life satisfaction of women with a lower perceived income than the Dutch.
} 
while the effect of high importance of income comparison with other immigrants is again strongly insignificant for those men with a higher household income than them. As a result, the total life satisfaction effect of high importance of income comparison with other immigrants and a higher household income is again strongly insignificant as well.

\section{Insert Table 8}

Considering the estimates for the cardinal specification for men in Table 8, we see that now attaching importance to income comparison with Dutch natives has a significant and positive life satisfaction effect, but in addition to that there is a significant and negative effect of the interaction of importance of income comparison with Dutch natives and household income relative to Dutch natives. ${ }^{32}$ At first sight, the negative sign of this interaction effect is counterintuitive as it implies a smaller relative income effect when Turkish immigrants attach a higher importance to income comparison with Dutch natives. However, it can also be interpreted in a more plausible way as indicating that the life satisfaction effect of importance of income comparison with Dutch natives is less positive when respondents perceive to have a higher household income relative to Dutch natives. So, for example when they perceive to have a lower household income in comparison with Dutch natives (score 2, which is reported by $36 \%$ of the men in the sample), the life satisfaction effect of importance of income comparison with Dutch natives equals $0.584-0.474 * \ln (2)=0.283$, which is significant and which is close to the overall effect of importance of income comparison with Dutch natives in the full sample estimation in Table 4 (0.239). On the other hand, the life satisfaction effect of importance of income comparison with Dutch natives for the mean value of ln household income relative to Dutch natives (0.832, corresponding to a relative income score of 2.30 ) is just not marginally significant $(\mathrm{p}=0.13)$ with size 0.207 . Thus, the positive effect of the emancipatory stimulus of income comparison with Dutch natives on the life satisfaction of male Turkish immigrants only seems to work for men who perceive their household income as (much) lower relative to Dutch natives. This effect appears to be the main driver of the significant life satisfaction effect of importance of income comparison with Dutch natives in the full sample estimation in Table 4. However, similarly to the full-sample dummy estimates in Table 3 , the positive effect on the life satisfaction of these Turkish men of a high importance of income comparison with Dutch natives is counteracted by the negative effect of their lower relative income. In particular, for the subsample averages of rather high and very high comparison importance (2.42) and lower and much lower $\ln$ relative income $(0.502=\ln (1.65))$, the total life satisfaction effect of high (as opposed to no)

\footnotetext{
${ }^{32}$ Such a significant interaction effect does not show up in the dummy estimation in Table 7, but when we add dummies for no as compared to moderate importance of income comparison with the Dutch (see Section 3) and their interaction terms with lower and higher income relative to the Dutch to this estimation, the interaction term with lower relative income is marginally significant $(p=0.09)$ with a negative sign, which is consistent with the negative sign of the interaction effect in the cardinal estimation in Table 8.
} 
importance of income comparison with Dutch natives and lower (as opposed to similar) income relative to Dutch natives is insignificant ( $\mathrm{p}=0.32$; estimated coefficient 0.32 ).

The effects of income comparison with other immigrants are all strongly insignificant in Table 8. In particular, in contrast with the significant coefficient of lower income than other immigrants in the dummy estimation in Table 7 , ln cardinal income relative to other immigrants has an insignificant effect on the life satisfaction of male Turkish immigrants.

\subsection{Subsample of the Turkish-consulate group}

We also investigated the robustness of the full-sample results to restricting this sample to the subsample of Turkish immigrants who were interviewed in the Turkish consulate, as the composition of this subsample turned out to differ from that of the subsample of Turkish immigrants who responded via the internet. ${ }^{33}$ As a result, the subsample from the Turkish consulate seems more homogeneous than the full sample including the internet subsample. Dropping the latter subsample from the full sample left us with at least 658 observations for the estimations with the ethnic reference groups and with at least 587 observations for the estimations with the life-domain reference groups. These numbers are higher than ten times the number of variables used, so the estimates are reliable. However, the internet subsample is much too small (maximally 148 observations) according to this criterion and led to estimation problems. Thus, we can only investigate the robustness of the full sample results to restricting the estimations to the Turkish-consulate subsample. For both the dummy and cardinal specifications of the ethnic-reference-group variables this led to results that are similar to, but a little bit more pronounced in terms of (in)significance than those for the full sample. This also holds for the estimation results for the cardinal specification of the life-domain-reference-group variables, but for the dummy specification of these reference variables we obtained results that are more differentiated than those for the full sample in Table 5. In particular, for the consulate subsample the coefficient estimates of two interaction terms were (marginally) significant, which, together with the coefficient estimates corresponding to those in Table 5, are presented in Table 9 (the other coefficients are insignificant).

\section{Insert Table 9 here}

For the reference group of colleagues, we again do not find significant effects. Furthermore, in agreement with the full-sample result in Table 5, a perceived lower income than neighbors has a significant and strongly negative impact on life satisfaction. Turkish immigrants are also much more satisfied if they attach a high importance to income comparison with relatives in the Netherlands, again indicating a collectivistic attitude towards these relatives. However, in contrast with the full-

\footnotetext{
${ }^{33}$ For example, in the consulate subsample $64 \%$ of the respondents are men versus $54 \%$ in the internet subsample while $13 \%$ have only elementary, $13 \%$ have only secondary, and $31 \%$ have only high-school education in the consulate subsample versus $1 \%, 3 \%$, and $14 \%$, respectively, in the internet subsample. On the other hand, $20 \%$ of the consulate subsample has undergraduate degrees against $39 \%$ of the internet subsample.
} 
sample result in Table 5, the life satisfaction effect of perceiving to have a higher income than them is now insignificant. Still, the total effect of high importance of income comparison with relatives in the Netherlands and a higher income than them is again insignificant.

Attaching a high importance to income comparison with relatives in other EU countries now has a strongly insignificant effect on the life satisfaction of Turkish immigrants, but instead there are two significant and negative interaction effects of high importance of income comparison with those relatives and perceiving to have a lower or higher income than them. The former interaction effect can most plausibly be interpreted as a lower income than relatives in other EU countries having a negative effect on life satisfaction when income comparison with relatives in other EU countries is perceived to be very important. ${ }^{34}$ Indeed, the total effect of a lower income than these relatives and its interaction with high importance of income comparison with them is significant and negative. In addition, the total life satisfaction effect of high importance of income comparison with relatives in other EU countries and a lower income than them is significant and negative as well.

The interaction effect of high importance of income comparison with relatives in other EU countries and a higher income than them may most plausibly be interpreted as a higher relative income having a negative life satisfaction effect when importance of income comparison with relatives in other EU countries is high. This interpretation is supported by the total effect of a higher income than these relatives and its interaction with a high importance of income comparison with them being marginally significant $(p=0.09)$ and negative. Moreover, the total life satisfaction effect of high importance of income comparison with EU relatives and a higher income than them is almost marginally significant $(p=0.11)$ and negative as well. These results look like a manifestation of collectivism as in the case of a negative life satisfaction effect of a higher income than relatives in the Netherlands. Thus, in this case of income comparison with relatives in other EU countries there appear to be a negative jealousy effect of a lower relative income as well as a negative collectivism effect of a higher relative income $!^{35}$ Finally, just as in the full sample, attaching a high importance to income comparison with relatives in Turkey has a significant and strongly negative effect on the life satisfaction of Turkish immigrants.

The presence of two significant interaction terms in this regression for the consulate subsample is somewhat surprising in view of their absence in the regression for the full sample in Table 5, which largely consists of consulate observations. However, both interaction terms were marginally significant in an earlier stage of the model selection for Table 5 (see the first paragraph of Section 4.2) and only became insignificant after subsequently dropping other insignificant interaction terms. Hence, they were dropped as well, but this made the coefficient of high importance of income comparison with relatives in other EU countries marginally significant in Table 5. Thus, this

\footnotetext{
${ }^{34}$ A number of respondents complained to the interviewers that relatives in Belgium and Germany had to pay lower taxes than they, leading to a higher net income of these relatives. Moreover, they complained that gasoline prices and houses are much cheaper in these countries.

${ }^{35}$ Note that a related ambiguity in the effects of comparison with relatives in other EU countries was found for the cardinal importance-of-comparison variable in the full-sample estimation of Table 6.
} 
coefficient picks up the effects of its dropped interactions with lower and higher relative income. As an improvement on this, Table 9 for the consulate subsample reveals a more differentiated structure of life satisfaction effects, which can thus also be detected for the full sample, but which did not show up in Table 5, probably due to the stronger heterogeneity of the full sample as a result of the difference in composition between the consulate and internet subsamples (see footnote 32).

\subsection{Dropping and adding control variables and causality}

Our regressions included the perceived level of life satisfaction of five years ago to control for spurious correlations between social-comparison variables and life satisfaction via time-invariant omitted variables like personality characteristics. We examined the potential effects of such spurious correlations by estimating our baseline equations without the perceived level of life satisfaction of five years ago as an explanatory variable. This did not yield essentially different estimates of the effects of the social comparison variables with some coefficients being somewhat more strongly significant and larger in size, but other coefficients being less significant. Thus, there was no indication of an important role of spurious correlations between social-comparison variables and life satisfaction. ${ }^{36} \mathrm{We}$ also investigated the possible effects of the five controls for perceived identity. The coefficients of these variables were jointly insignificant in all baseline regressions, and accordingly, dropping them yielded social-comparison effects that are very similar to the baseline results. However, still the positive life satisfaction effect of finding it important to compare one's income with Dutch natives may pick up a positive effect on life satisfaction of being well integrated in Dutch society. For example, Van der Houwen and Moonen (2014) find that feeling at home in the Netherlands had a significant positive effect on the life satisfaction of Turkish immigrants in 2011 (see also Angelini et al., 2015). Accordingly, when we added a dummy variable for feeling that you belong to the Netherlands as an additional control variable from our dataset to the dummy-specification for ethnic reference groups in Table 3, we found a significant positive effect on life satisfaction while the coefficient of high importance of income comparison with the Dutch was smaller than in Table 3 (0.317 vs. 0.347$)$, but still significant.

It is also possible that the significant correlations of the social-comparison variables with life satisfaction that we found are partially driven by reverse causality. For example, Turkish immigrants may find it more important to compare their household income with those of Dutch natives if they are more satisfied with their life (see the pertinent significant and positive coefficients in Tables 3 and 4). To control for this possibility we tried to find a valid and sufficiently strong instrument for high importance of income comparison with Dutch natives in our data set, but we did not succeed in finding

\footnotetext{
${ }^{36}$ By the same token, a potential upward bias in the coefficient of perceived life satisfaction of five years ago due to anchoring one's memory of the past in the present (Hastie and Dawes, 2010, Sect. 4.4) does not essentially affect the results. Anchoring one's memory of the past in the present is the phenomenon that the memory of one's own attitudes in the past is strongly positively influenced by one's current attitudes. In our life satisfaction case, this would imply a positive endogeneity bias in the coefficient of perceived life satisfaction of five years ago.
} 
a valid instrument that was strong enough according to the Cragg-Donald F-statistic (much lower than 10). To control for the possibility that Turkish immigrants may perceive to have a lower income than Dutch natives if they are less satisfied with life (see the pertinent strongly significant and negative coefficients in Tables 3 and 4), we also tried to find a valid and sufficiently strong instrument for lower perceived income than Dutch natives. In this case we did find a valid instrument that seemed just strong enough, namely the ln household income bracket variable ${ }^{37}$ (Cragg-Donald F-stat. = 12.5), but instrumenting lower income than Dutch natives by this variable produced an insignificant negative coefficient $(\mathrm{p}=0.32)$. Applying the Hansen J-statistic endogeneity test did not yield a rejection of equality of this IV estimate to the OLS estimate, but because the IV estimate is imprecise, this test is not very informative. Similar results were obtained when we instrumented $\ln$ (income in comparison to Dutch natives) by $\ln$ (income) in the cardinal specification of Table 4 (C-D F-stat. $=27.2$, insignificant positive coefficient with $\mathrm{p}=0.30$, not significantly different from OLS estimate) and higher income than relatives in NL by income in the dummy specification of Table 5 (C-D F-stat. = 18.2, insignificant negative coefficient with $p=0.71$, not significantly different from OLS estimate). For the other relative income variables with significant OLS coefficients $\ln$ (income) or income is a much too weak instrument. Thus, overall we do not find indications of reverse causality from perceived income relative to various reference groups towards life satisfaction, but the evidence is inconclusive.

Mayraz et al. (2009, Section 6) try to test for such reverse causality by regressing each of their cardinal relative income variables on life satisfaction, an interaction of life satisfaction with the perceived importance of the relative income comparison concerned, and the other control variables, and by examining whether the interaction effect is significantly positive. However, in our view this procedure is not a valid reverse-causality test, but only tests whether the (positive) correlation between each relative income variable and life satisfaction positively depends on the perceived importance of the relative income comparison, conditional on the other control variables. For example, when we applied such a test to the higher-income-than-relatives-in-NL variable in the dummy specification of Table 5, we found a marginally significant and positive interaction effect, which, however, only forms the mirror image of the marginally significant and positive interaction effect of high importance of income comparison with relatives in $\mathrm{NL}$ and higher income than them on life satisfaction in the regression of Table 9. Accordingly, for the other relative-income variables with significant coefficients, but insignificant interaction effects with the corresponding importance-of-incomecomparison variable in our life satisfaction regressions, the test of Mayraz et al. yielded insignificant interaction effects as well.

\footnotetext{
${ }^{37} \mathrm{We}$ assume that this variable is a valid instrument as it is strongly insignificant in the baseline regression of Table 3.
} 


\section{Conclusion}

This study has analysed the effects of social comparison with a wide range of reference groups on the life satisfaction of Turkish immigrants in the Netherlands. Two sets of social reference groups were distinguished, ethnic reference groups and life-domain reference groups, and their impact on life satisfaction was separately analysed in regression estimations with alternatively dummy or cardinal specifications of the variables for perceived importance of income comparison and perceived relative incomes. For both sets of reference groups results were obtained that deviate from the findings of recent studies on the effects of social comparison and that suggest the impact of the collectivistic subculture of the Turkish immigrants. In the case of the ethnic reference groups, perceived importance of income comparison with Dutch natives is significantly and positively correlated to life satisfaction, which supports an interpretation of this comparison as a positive emancipatory stimulus in the pursuit of self-improvement of the Turkish immigrants. In the case of the life-domain reference groups, perceived importance of income comparison with relatives in the Netherlands is significantly and positively correlated to life satisfaction as well, which can be interpreted in terms of an underlying feeling of connectedness with one's relatives. On the other hand, Turkish immigrants who have a higher household income than relatives are significantly less satisfied with their life, suggesting the unattractiveness of deviating too much from one's relatives. For the perceived importance of income comparison with relatives in other EU countries the evidence is more mixed with a positive correlation with life satisfaction for a moderate degree of importance and a negative correlation for a high degree of importance. For both sets of reference groups some other interesting results were obtained as well.

While we tried to control for spurious correlations between the income comparison variables and life satisfaction by the perceived level of life satisfaction five years ago, instrumenting the relative income variables by absolute income did not yield indications of reverse causality. However, the evidence is inconclusive, and so the direction of causality between perceived relative income and life satisfaction as well as between perceived importance of income comparison and life satisfaction remains an open question for further research. 


\section{References}

Angelini, V., Casi, L., Corazzini, L., 2015. Life satisfaction of immigrants: Does cultural assimilation matter? Journal of Population Economics, 28, 817-844.

Bartram, D., 2010. International migration, open borders debates, and happiness. International Studies Review, 12(3), 339-361.

Card, D., Mas, A., Moretti, E., Saez, E., 2012. Inequality at work: The effect of peer salaries on job satisfaction. American Economic Review, 102(6), 2981-3003.

Carter, S., McBride, M., 2013. Experienced utility versus decision utility: Putting the " $S$ " in satisfaction. Journal of Behavioral and Experimental Economics, 42(C), 13-23.

Clark, A.E., Oswald, A.J., 1996. Satisfaction and comparison income. Journal of Public Economics $61,359-381$.

Clark, A.E., Senik, C., 2010. Who compares to whom? The autonomy of income comparisons in Europe. Economic Journal 120, 573-594.

Chung, T., Mallery, P., 1999/2000. Social comparison, individualism-collectivism, and self-esteem in China and the United States. Current Psychology, 18(4), 340-352.

Cornelisse-Vermaat, J. R., 2005. Household production, health, and happiness: A comparison of the native Dutch and non-western immigrants in the Netherlands. PhD thesis, Wageningen University, The Netherlands.

D'Ambrosio, C., Frick, J.R., 2012. Individual wellbeing in a dynamic perspective. Economica, 79(314), 284-302.

Fehr, E., Schmidt, K.M., 1999. A theory of fairness, competition, and cooperation. Quarterly Journal of Economics 114, 817-868.

Ferrer-i-Carbonell, A., 2005. Income and well-being: an empirical analysis of the comparison income effect. Journal of Public Economics, 89(5), 997-1019.

Goerke, L., Pannenberg, M., 2013. Direct evidence on income comparisons and subjective well-being. Working paper. IAAEU, University of Trier, Germany.

Gokdemir, O., Dumludag, D., 2010. Happiness among Turkish and Moroccan immigrants in the Netherlands. The International Journal of Interdisciplinary Social Sciences, 5(6), 155-166.

Gokdemir, O., Dumludag, D., 2011. Life satisfaction among Turkish and Moroccan immigrants in the Netherlands: The role of absolute and relative income. Social Indicators Research, 106(3), 407-417.

Hastie, R., Dawes, R.M., 2010. Rational choice in an uncertain world: The psychology of judgment and decision making. Sage, London.

Hofstede, G., 1984. Culture's consequences: International differences in work-related values. Beverly Hills, CA: Sage Publications

Layard, R., Mayraz, G., Nickell, S., 2010. Does relative income matter? Are the critics right? In: Diener, E., Helliwell, J., Kahneman, D. (Eds.), International Differences in Well-Being. Oxford University Press, New York.

Leites, M., 2015. Essays on the role of social status and beliefs on intergenerational mobility. PhD thesis. Universitat Autonoma de Barcelona. 
Luttmer, E., 2005. Neighbors as negatives: relative earnings and well-being. Quarterly Journal of Economics 120, 963-1002.

Mayraz, G., Wagner, G. G., Schupp, J., 2009. Life satisfaction and relative income: perceptions and evidence. IZA Discussion Paper No. 4390. IZA, Bonn.

Montizaan, R.M., Vendrik, M.C.M., 2014. Misery loves company: Exogenous shocks in retirement expectations and social comparison effects on well-being. Journal of Economic Behavior and Organization, 97: 1-26.

McBride, M., 2001. Relative-income effects on subjective well-being in the cross-section. Journal of Economic Behavior and Organization, 45(3), 251-278.

Phalet, K., Schönpflug, U. (2001), Intergenerational transmission of collectivism and achievement values in two acculturation contexts: The case of Turkish families in Germany and Turkish and Moroccan families in the Netherlands. Journal of Cross-Cultural Psychology, 32(2), 186201.

Safi, M., (2010). Immigrants' life satisfaction in Europe: Between assimilation and discrimination. European Sociological Review, 26(2), 159-176.

Schwartz, B., Ward, A., Monterosso, J., Lyubomirsky, S., White, K., Lehman, D. R., 2002. Maximizing versus satisficing: Happiness as a matter of choice. Journal of Personality and Social Psychology, 83 (5), 1178-1197.

Senik, C., 2009. Direct evidence on income comparisons and their welfare effects. Journal of Economic Behavior and Organization, 72(1), 408-424.

Van der Houwen, K., Moonen, L., 2014. Allochtonen en geluk. Bevolkingstrends October 2014. Statistics Netherlands, Den Haag.

Van Praag, B.M.S., Ferrer-i-Carbonell, A., 2004. Happiness Quantified: A Satisfaction Calculus Approach. Oxford University Press, Oxford.

Vendrik, M., 2013. Adaptation, anticipation and social interaction in happiness: An integrated errorcorrection approach. Journal of Public Economics, 105, 131-149.

Verkuyten, M., (1986). The impact of ethnic and sex differences on happiness among adolescents in the Netherlands. Journal of Social Psychology, 126, 259-260.

Verkuyten, M., (2008). Life satisfaction among ethnic minorities: The role of discrimination and group identification. Social Indicators Research, 89, 391-404.

White, K., Lehman, D. R., 2005. Culture and social comparison seeking: The role of selfmotives. Personality and Social Psychology Bulletin, 31(2), 232-242. 
Table 1. Perceived importance of income comparison and perceived relative income for ethnic reference groups of Turkish immigrants

\begin{tabular}{lcccc}
\hline Reference Group & Dutch natives & Turkish immigrants & Other immigrants & People in Turkey \\
\hline & Perceived importance of income comparison (in \%) & & \\
\hline Completely unimportant & 19.2 & 20.3 & 44.0 & 15.9 \\
Rather important & 49.0 & 49.0 & 43.7 & 42.2 \\
Very Important & 31.8 & 30.7 & 12.3 & 41.7 \\
\hline Mean & 2.13 & 2.10 & 1.68 & 2.26 \\
Standard Error & 0.70 & 0.71 & 0.68 & 0.71 \\
\hline Number of observations & 927 & 928 & 913 & 917 \\
\hline & & Perceived relative income (in \%) & 4.3 \\
\hline Much lower & 14.0 & 4.2 & 4.3 & 12.9 \\
Lower & 36.3 & 12.5 & 12.2 & 25.0 \\
About the same & 40.2 & 55.7 & 48.0 & 42.1 \\
Higher & 8.6 & 24.7 & 31.3 & 15.7 \\
Much higher & 0.9 & 2.9 & 4.3 & 3.52 \\
\hline Mean & 2.46 & 3.10 & 3.19 & 1.04 \\
Standard Error & 0.87 & 0.80 & 0.86 & 929 \\
\hline Number of observations & 956 & 928 & 905 & \\
\hline
\end{tabular}

Table 2. Perceived importance of income comparison and perceived relative income for life-domain reference groups of Turkish immigrants

\begin{tabular}{|c|c|c|c|c|c|}
\hline Reference Group & Colleagues & Neighbors & $\begin{array}{l}\text { Relatives in the } \\
\text { Netherlands }\end{array}$ & Relatives in EU & $\begin{array}{c}\text { Relatives in } \\
\text { Turkey }\end{array}$ \\
\hline \multicolumn{6}{|c|}{ Perceived importance of income comparison (in \%) } \\
\hline $\begin{array}{l}\text { Completely } \\
\text { unimportant }\end{array}$ & 24.10 & 34.18 & 24.56 & 32.66 & 20.24 \\
\hline Rather important & 51.24 & 51.32 & 48.56 & 48.48 & 48.64 \\
\hline Very Important & 24.66 & 14.51 & 26.88 & 18.86 & 31.12 \\
\hline Mean & 2.01 & 1.80 & 2.02 & 1.86 & 2.11 \\
\hline Standard Error & 0.70 & 0.67 & 0.72 & 0.70 & 0.71 \\
\hline $\begin{array}{l}\text { Number of } \\
\text { observations }\end{array}$ & 888 & 910 & 904 & 891 & 919 \\
\hline \multicolumn{6}{|c|}{ Perceived relative income (in \%) } \\
\hline Much lower & 5.05 & 3.77 & 5.22 & 8.62 & 3.20 \\
\hline Lower & 13.42 & 16.85 & 14.00 & 32.63 & 13.54 \\
\hline About the same & 58.26 & 60.98 & 58.00 & 36.71 & 26.97 \\
\hline Higher & 19.38 & 17.18 & 20.78 & 20.05 & 46.48 \\
\hline Much higher & 3.90 & 1.22 & 2.00 & 1.98 & 9.81 \\
\hline Mean & 3.04 & 2.95 & 3.00 & 2.74 & 3.46 \\
\hline Standard Error & 0.83 & 0.73 & 0.80 & 0.94 & 0.95 \\
\hline $\begin{array}{l}\text { Number of } \\
\text { observations }\end{array}$ & 872 & 902 & 900 & 858 & 938 \\
\hline
\end{tabular}


Table 3. OLS estimates of coefficients and derived effects of dummy variables for ethnic reference groups

\begin{tabular}{|c|c|c|}
\hline $\begin{array}{l}\text { Dependent variable: } \\
\text { Life satisfaction }(0-10)\end{array}$ & $\begin{array}{l}\text { Estimated } \\
\text { effect }\end{array}$ & $\begin{array}{l}\text { Standard } \\
\text { error }\end{array}$ \\
\hline High importance of income comparison with Dutch natives & $0.347 * *$ & 0.151 \\
\hline Lower income than Dutch natives & $-0.546 * * *$ & 0.160 \\
\hline Higher income than Dutch natives & 0.121 & 0.198 \\
\hline High importance of income comparison with other immigrants & $-0.740 * *$ & 0.326 \\
\hline Lower income than other immigrants & 0.082 & 0.284 \\
\hline Higher income than other immigrants & -0.074 & 0.165 \\
\hline $\begin{array}{l}\text { High importance of income comparison with other immigrants } \mathrm{x} \text { higher } \\
\text { income than other immigrants (interaction) }\end{array}$ & $0.897 * *$ & 0.413 \\
\hline Worse living standard than parents & $-0.802 * * *$ & 0.249 \\
\hline Better living standard than parents & $0.501 * * *$ & 0.173 \\
\hline Ln income & 0.114 & 0.140 \\
\hline $\begin{array}{l}\text { High importance of income comparison with Dutch natives + lower } \\
\text { income than Dutch natives }\end{array}$ & -0.199 & 0.210 \\
\hline $\begin{array}{l}\text { High importance of income comparison with Dutch natives }+ \text { higher } \\
\text { income than Dutch natives }\end{array}$ & $0.468 *$ & 0.237 \\
\hline $\begin{array}{l}\text { High importance of income comparison with other immigrants + lower } \\
\text { income than other immigrants }\end{array}$ & -0.658 & 0.411 \\
\hline Higher income than other immigrants + interaction & $0.823^{*}$ & 0.415 \\
\hline $\begin{array}{l}\text { High importance of income comparison with other immigrants + } \\
\text { interaction }\end{array}$ & 0.157 & 0.288 \\
\hline $\begin{array}{l}\text { High importance of income comparison with other immigrants }+ \text { higher } \\
\text { income than other immigrants + interaction }\end{array}$ & 0.083 & 0.305 \\
\hline Number of observations & 757 & \\
\hline Adjusted R-squared & 0.370 & \\
\hline
\end{tabular}

Note: $* * *=\mathrm{p}<0.01, * *=\mathrm{p}<0.05, *=\mathrm{p}<0.10$.

Table 4. OLS estimates of coefficients of cardinal variables for ethnic reference groups

\begin{tabular}{lll}
\hline $\begin{array}{l}\text { Dependent variable: } \\
\text { Life satisfaction (0-10) }\end{array}$ & $\begin{array}{l}\text { Estimated } \\
\text { coefficient }\end{array}$ & $\begin{array}{l}\text { Standard } \\
\text { error }\end{array}$ \\
\hline Importance of income comparison with Dutch natives & $0.239^{* *}$ & 0.102 \\
Ln income in comparison to Dutch natives & $0.691^{* * *}$ & 0.202 \\
(Importance of income comparison with other immigrants) $^{4}$ & $-0.017^{*}$ & 0.009 \\
Ln income in comparison to other immigrants & -0.265 & 0.358 \\
${\text { (Importance of income comparison with other immigrants) }{ }^{4} \mathrm{x} \text { ln income }}^{\text {in comparison with other immigrants (interaction) }}$ & 0.012 & 0.007 \\
Worse living standard than parents & $-0.817^{* * *}$ & 0.248 \\
Better living standard than parents & $0.453^{* * * *}$ & 0.171 \\
Ln income & 0.090 & 0.139 \\
\hline Observations & 758 & \\
Adjusted R-squared & 0.374 & \\
\hline
\end{tabular}

Note: $* * * \mathrm{p}<0.01, * *=\mathrm{p}<0.05, *=\mathrm{p}<0.10$. 
Table 5. OLS estimates of coefficients and derived effects of dummy variables for lifedomain reference groups

\begin{tabular}{|c|c|c|}
\hline $\begin{array}{l}\text { Dependent variable: } \\
\text { Life satisfaction }(0-10)\end{array}$ & $\begin{array}{l}\text { Estimated } \\
\text { effect }\end{array}$ & $\begin{array}{l}\text { Standard } \\
\text { error }\end{array}$ \\
\hline Lower income than neighbours & $-0.729 * * *$ & 0.238 \\
\hline High importance of income comparison with relatives in the Netherlands & $0.467 * *$ & 0.201 \\
\hline Lower income than relatives in the Netherlands & -0.083 & 0.242 \\
\hline Higher income than relatives in the Netherlands & $-0.412 *$ & 0.214 \\
\hline $\begin{array}{l}\text { High importance of income comparison with relatives in other EU } \\
\text { countries }\end{array}$ & $-0.427 *$ & 0.245 \\
\hline High importance of income comparison with relatives in Turkey & $-0.435 * *$ & 0.186 \\
\hline Worse living standard than parents & $-0.836 * * *$ & 0.253 \\
\hline Better living standard than parents & 0.313 & 0.182 \\
\hline Ln income & 0.076 & 0.148 \\
\hline $\begin{array}{l}\text { High importance of income comparison with relatives in the Netherlands } \\
+ \text { higher income than relatives in the Netherlands }\end{array}$ & 0.055 & 0.284 \\
\hline Observations & 653 & \\
\hline Adjusted R-squared & 0.379 & \\
\hline
\end{tabular}

Note: $* * *=\mathrm{p}<0.01, * *=\mathrm{p}<0.05, *=\mathrm{p}<0.10$.

Table 6. OLS estimates of coefficients and derived effects of cardinal variables for lifedomain reference groups

\begin{tabular}{|c|c|c|}
\hline $\begin{array}{l}\text { Dependent variable: } \\
\text { Life satisfaction (0-10) }\end{array}$ & $\begin{array}{l}\text { Estimated } \\
\text { effect }\end{array}$ & $\begin{array}{l}\text { Standard } \\
\text { error }\end{array}$ \\
\hline Ln income in comparison to neighbours & $1.019 * * *$ & 0.378 \\
\hline Importance of income comparison with relatives in the Netherlands & $0.215^{*}$ & 0.125 \\
\hline Income in comparison to relatives in the Netherlands & 0.456 & 0.452 \\
\hline (Income in comparison to relatives in the Netherlands) ${ }^{2}$ & -0.100 & 0.068 \\
\hline Importance of income comparison with relatives in other EU countries & $1.332 * *$ & 0.549 \\
\hline $\begin{array}{l}\text { (Importance of income comparison with relatives in other EU } \\
\text { countries) })^{2}\end{array}$ & $-0.346^{* *}$ & 0.143 \\
\hline Importance of income comparison with relatives in Turkey & $-0.308 * *$ & 0.126 \\
\hline Worse living standard than parents & $0.826 * * *$ & 0.247 \\
\hline Better living standard than parents & $0.373 * *$ & 0.181 \\
\hline Ln income & 0.100 & 0.149 \\
\hline $\begin{array}{l}\Delta \text { (Importance of income comparison with relatives in other EU } \\
\text { countries })=2-1 \\
\Delta \text { (Importance of income comparison with relatives in other EU } \\
\text { countries })=3-2\end{array}$ & $-0.401 *$ & 0.170 \\
\hline Observations & 653 & \\
\hline Adjusted R-squared & 0.379 & \\
\hline \multicolumn{3}{|c|}{$\begin{array}{l}\text { Note: } * * *=p<0.01, * *=p<0.05, *=p<0.10 \text {. The first derived effect in the second panel of Table } 6 \\
\text { represents the effect of an increase in the importance of income comparison with EU relatives from } 1(= \\
\text { completely unimportant) to } 2 \text { (= rather important) and equals the coefficient of the linear term plus } 3 \times \\
\text { the coefficient of the quadratic term. The second derived effect in the second panel of Table } 4 \text { represents } \\
\text { the effect of an increase in the importance of income comparison with EU relatives from } 2 \text { (= rather } \\
\text { important) to } 3 \text { (= very important) and equals the coefficient of the linear term plus } 5 \times \text { the coefficient of } \\
\text { the quadratic term. }\end{array}$} \\
\hline
\end{tabular}


Table 7. OLS estimates of coefficients and derived effects of dummy variables for ethnic reference groups for men

\begin{tabular}{|c|c|c|}
\hline $\begin{array}{l}\text { Dependent variable: } \\
\text { Life satisfaction }(0-10)\end{array}$ & $\begin{array}{l}\text { Estimated } \\
\text { effect }\end{array}$ & $\begin{array}{l}\text { Standard } \\
\text { error }\end{array}$ \\
\hline High importance of income comparison with Dutch natives & 0.210 & 0.187 \\
\hline Lower income than Dutch natives & $-0.505 * *$ & 0.196 \\
\hline Higher income than Dutch natives & -0.048 & 0.248 \\
\hline High importance of income comparison with other immigrants & -0.650 & 0.402 \\
\hline Lower income than other immigrants & $-0.862 * *$ & 0.386 \\
\hline Higher income than other immigrants & 0.014 & 0.216 \\
\hline $\begin{array}{l}\text { High importance of income comparison with other immigrants } x \text { higher } \\
\text { income than other immigrants (interaction) }\end{array}$ & 0.699 & 0.475 \\
\hline Worse living standard than parents & $-1.068 * * *$ & 0.310 \\
\hline Better living standard than parents & 0.115 & 0.208 \\
\hline Ln income & 0.152 & 0.188 \\
\hline $\begin{array}{l}\text { High importance of income comparison with Dutch natives + lower } \\
\text { income than Dutch natives }\end{array}$ & -0.296 & 0.256 \\
\hline $\begin{array}{l}\text { High importance of income comparison with Dutch natives }+ \text { higher } \\
\text { income than Dutch natives }\end{array}$ & 0.162 & 0.298 \\
\hline $\begin{array}{l}\text { High importance of income comparison with other immigrants }+ \text { lower } \\
\text { income than other immigrants }\end{array}$ & $-1.512 * * *$ & 0.527 \\
\hline Higher income than other immigrants + interaction & 0.713 & 0.481 \\
\hline $\begin{array}{l}\text { High importance of income comparison with other immigrants + } \\
\text { interaction }\end{array}$ & 0.049 & 0.309 \\
\hline $\begin{array}{l}\text { High importance of income comparison with other immigrants }+ \text { higher } \\
\text { income than other immigrants }+ \text { interaction }\end{array}$ & 0.063 & 0.336 \\
\hline Observations & 469 & \\
\hline Adjusted R-squared & 0.402 & \\
\hline
\end{tabular}

Note: $* * *=p<0.01, * *=p<0.05, *=p<0.10$.

Table 8. OLS estimates of coefficients of cardinal variables for ethnic reference groups for men

\begin{tabular}{|c|c|c|}
\hline $\begin{array}{l}\text { Dependent variable: } \\
\text { Life satisfaction }(0-10)\end{array}$ & $\begin{array}{l}\text { Estimated } \\
\text { coefficient }\end{array}$ & $\begin{array}{l}\text { Standard } \\
\text { error }\end{array}$ \\
\hline Importance of income comparison with Dutch natives & $0.664 * *$ & 0.270 \\
\hline Ln income in comparison to Dutch natives & $1.832 * * *$ & 0.642 \\
\hline $\begin{array}{l}\text { (Importance of income comparison with Dutch natives) } \mathrm{x} \ln \text { income in } \\
\text { comparison with Dutch natives (interaction) }\end{array}$ & $-0.550 * *$ & 0.267 \\
\hline (Importance of income comparison with other immigrants) ${ }^{4}$ & -0.012 & 0.012 \\
\hline Ln income in comparison to other immigrants & 0.391 & 0.532 \\
\hline $\begin{array}{l}\text { (Importance of income comparison with other immigrants })^{4} \mathrm{x} \ln \text { income } \\
\text { in comparison to other immigrants }\end{array}$ & 0.008 & 0.010 \\
\hline Worse living standard than parents & $-1.020 * * *$ & 0.310 \\
\hline Better living standard than parents & 0.119 & 0.203 \\
\hline Ln income & 0.129 & 0.189 \\
\hline Observations & 470 & \\
\hline Adjusted R-squared & 0.406 & \\
\hline
\end{tabular}

Note: $* * *=\mathrm{p}<0.01, * *=\mathrm{p}<0.05, *=\mathrm{p}<0.10$. 
Table 9. OLS estimates of coefficients and derived effects of dummy variables for life-domain reference groups for the consulate sample

\begin{tabular}{|c|c|c|}
\hline $\begin{array}{l}\text { Dependent variable: } \\
\text { Life satisfaction }(0-10)\end{array}$ & $\begin{array}{l}\text { Estimated } \\
\text { effect }\end{array}$ & $\begin{array}{l}\text { Standard } \\
\text { error }\end{array}$ \\
\hline Lower income than neighbors & $-0.616 * *$ & 0.257 \\
\hline High importance of income comparison with relatives in the Netherlands & $0.554 * * *$ & 0.209 \\
\hline Lower income than relatives in the Netherlands & -0.020 & 0.271 \\
\hline Higher income than relatives in the Netherlands & -0.277 & 0.232 \\
\hline High importance of income comparison with relatives in other EU countries & 0.052 & 0.317 \\
\hline Lower income than relatives in other EU countries & 0.034 & 0.204 \\
\hline Higher income than relatives in other EU countries & 0.172 & 0.242 \\
\hline $\begin{array}{l}\text { High importance of income comparison with relatives in other EU countries } x \\
\text { lower income than relatives in other EU countries (interaction) }\end{array}$ & $-0.882 * *$ & 0.433 \\
\hline $\begin{array}{l}\text { High importance of income comparison with relatives in other EU countries } x \\
\text { higher income than relatives in other EU countries (interaction) }\end{array}$ & $-0.851 * * *$ & 0.428 \\
\hline High importance of income comparison with relatives in Turkey & $-0.415^{* *}$ & 0.193 \\
\hline Worse living standard than parents & $-0.881 * * *$ & 0.258 \\
\hline Better living standard than parents & $0.330 *$ & 0.186 \\
\hline Ln income & 0.141 & 0.156 \\
\hline $\begin{array}{l}\text { High importance of income comparison with relatives in the Netherlands + higher } \\
\text { income than relatives in the Netherlands }\end{array}$ & 0.277 & 0.301 \\
\hline $\begin{array}{l}\text { Lower income than relatives in other EU countries }+ \text { high importance of income } \\
\text { comparison with relatives in other EU countries x lower income than relatives in } \\
\text { other EU countries (interaction) }\end{array}$ & $-0.849 * *$ & 0.413 \\
\hline $\begin{array}{l}\text { High importance of income comparison with relatives in other EU countries }+ \\
\text { lower income than relatives in other EU countries }+ \text { interaction }\end{array}$ & $-0.797 * *$ & 0.393 \\
\hline $\begin{array}{l}\text { Higher income than relatives in other EU countries + high importance of income } \\
\text { comparison with relatives in other EU countries x higher income than relatives in } \\
\text { other EU countries (interaction) }\end{array}$ & $-0.679 *$ & 0.401 \\
\hline $\begin{array}{l}\text { High importance of income comparison with relatives in other EU countries + } \\
\text { higher income than relatives in other EU countries + interaction }\end{array}$ & $-0.627 *$ & 0.397 \\
\hline Observations & 593 & \\
\hline Adjusted R-squared & 0.395 & \\
\hline
\end{tabular}

Note: $* * *=p<0.01, * *=p<0.05, *=p<0.10$. 


\section{Appendix A. Survey questions on income comparison}

When you think about the income of your household, how important is it for you to compare that income to those of the following groups?

\section{Groups}

Dutch natives

Other Turkish immigrants in the Netherlands

Other immigrants in the Netherlands

People living in Turkey

\section{Completely unimportant}

(1)

(1)

\section{Rather important}

(2)

(2)

\section{Very important}

(3)

And how high is the income of your household in comparison with the following groups?

\section{Groups}

Dutch natives

Other Turkish immigrants in the Netherlands

Other immigrants in the Netherlands

People living in Turkey

\section{Much lower}

(1)

\section{Lower}

(2)

(2)

(2)

\section{About the same}

Higher Much higher

\author{
(4)
}

(5)

(3)

(4)

(5)

(3)

(4)

(5)

(3)

When you think about the income of your household, how important is it for you to compare that income to those of the following groups?

\section{Groups}

Relatives living in the Netherlands

Relatives living in other EU countries

Relatives living in Turkey

Neighbours in the Netherlands

Colleagues/classmates

\section{Completely unimportant}

(1)

(1)

(1)

\section{Rather important}

(2)

(2)

(2)

(2)

(2)
Very important

And how high is the income of your household in comparison with the following groups?

\section{Groups}

Relatives living in the Netherlands

Relatives living in other EU countries

Relatives living in Turkey

Neighbours in the Netherlands

Colleagues/classmates

$\begin{array}{ccccc}\text { Much lower } & \text { Lower } & \begin{array}{c}\text { About the } \\ \text { same }\end{array} & \text { Higher } & \text { Much higher } \\ (1) & (2) & (3) & (4) & (5) \\ (1) & (2) & (3) & (4) & (5) \\ (1) & (2) & (3) & (4) & (5) \\ (1) & (2) & (3) & (4) & (5) \\ (1) & (2) & (3) & (4) & (5)\end{array}$




\section{Appendix B. Descriptive statistics}

Table B.1. Descriptive statistics of life satisfaction and control variables for full sample in comparison with subsample of Dutch Labour Force Survey (EBB) of those with Turkish nationality and age 16-73

\begin{tabular}{|c|c|c|c|c|c|c|}
\hline & Mean & Std. dev. & Min-max & $\begin{array}{l}\text { Mean } \\
\text { EBB }^{1}\end{array}$ & $\begin{array}{c}\text { St. dev. } \\
\text { EBB }\end{array}$ & $\begin{array}{c}\text { Min-Max } \\
\text { EBB }\end{array}$ \\
\hline Life satisfaction & 6.72 & 2.21 & $0-10$ & & & \\
\hline $\begin{array}{l}\text { Remembered life satisfaction } \\
\text { five years ago }\end{array}$ & 7.03 & 2.23 & $0-10$ & & & \\
\hline Household income & 3.87 & 2.48 & $1-10$ & & & \\
\hline \multicolumn{7}{|l|}{ Living standard: } \\
\hline Worse than parents & 0.61 & 0.49 & $0-1$ & & & \\
\hline Similar to parents & 0.21 & 0.41 & $0-1$ & & & \\
\hline Better than parents & 0.18 & 0.38 & $0-1$ & & & \\
\hline \multicolumn{7}{|l|}{ Demographic } \\
\hline Gender & 0.63 & 0.48 & $0-1$ & 0.52 & 0.50 & $0-1$ \\
\hline Age & 36.0 & 10.2 & $16-74$ & 37.2 & 11.8 & $16-73$ \\
\hline Generation & 1.41 & 0.45 & $1-2.5$ & 1.14 & 0.40 & $1-2$ \\
\hline Household size & 3.56 & 1.45 & $1-\geq 10$ & 3.53 & 1.32 & $1-7$ \\
\hline Number of children & 1.46 & 1.41 & $0-9$ & $1.59^{2}$ & 1.15 & $0-5$ \\
\hline \multicolumn{7}{|l|}{ Marital status } \\
\hline Married/living together & 0.64 & 0.48 & $0-1$ & $0.67^{3}$ & 0.47 & $0-1$ \\
\hline Widowed & 0.01 & 0.07 & $0-1$ & 0.01 & 0.12 & $0-1$ \\
\hline Separated/divorced & 0.10 & 0.30 & $0-1$ & 0.11 & 0.31 & $0-1$ \\
\hline Single & 0.25 & 0.44 & $0-1$ & $0.20^{4}$ & 0.40 & $0-1$ \\
\hline \multicolumn{7}{|l|}{ Education } \\
\hline Elementary & 0.11 & 0.32 & $0-1$ & 0.29 & 0.45 & $0-1$ \\
\hline Secondary & 0.11 & 0.31 & $0-1$ & 0.25 & 0.43 & $0-1$ \\
\hline High school & 0.28 & 0.45 & $0-1$ & 0.09 & 0.28 & $0-1$ \\
\hline Vocational & 0.23 & 0.42 & $0-1$ & 0.25 & 0.43 & $0-1$ \\
\hline Undergraduate & 0.23 & 0,42 & $0-1$ & 0.04 & 0.20 & $0-1$ \\
\hline Postgraduate & 0.03 & 0.17 & $0-1$ & 0.04 & 0.19 & $0-1$ \\
\hline \multicolumn{7}{|l|}{ Employment } \\
\hline Full-time & 0.37 & 0.48 & $0-1$ & 0.31 & 0.46 & $0-1$ \\
\hline Part-time & 0.14 & 0.35 & $0-1$ & 0.15 & 0.36 & $0-1$ \\
\hline Self-employed & 0.15 & 0.36 & $0-1$ & 0.08 & 0.27 & $0-1$ \\
\hline Retired & 0.02 & 0.16 & $0-1$ & & & \\
\hline Housewife & 0.03 & 0.18 & $0-1$ & & & \\
\hline Student & 0.09 & 0.29 & $0-1$ & 0.09 & 0.28 & $0-1$ \\
\hline Non-working & 0.18 & 0.39 & $0-1$ & $0.40^{5}$ & 0.49 & $0-1$ \\
\hline \multicolumn{7}{|l|}{ Socio-cultural } \\
\hline Religion & 3.10 & 3.10 & $0-5$ & & & \\
\hline \multicolumn{7}{|l|}{ Identity } \\
\hline Turkish & 0.46 & 0.55 & $0-1$ & & & \\
\hline Muslim & 0.36 & 0.54 & $0-1$ & & & \\
\hline Dutch citizen & 0.03 & 0.30 & $0-1$ & & & \\
\hline World citizen & 0.12 & 0.40 & $0-1$ & & & \\
\hline Other & 0.03 & 0.30 & $0-1$ & & & \\
\hline
\end{tabular}




\section{Appendix C. Full estimations results}

Table C.1. OLS estimates of coefficients of all dummy variables for ethnic reference groups and all control variables

\begin{tabular}{|c|c|c|}
\hline $\begin{array}{l}\text { Dependent variable: } \\
\text { Life satisfaction }(0-10)\end{array}$ & $\begin{array}{l}\text { Estimated } \\
\text { coefficient }\end{array}$ & $\begin{array}{l}\text { Standard } \\
\text { error }\end{array}$ \\
\hline High importance of income comparison with Dutch natives & $0.347 * *$ & 0.151 \\
\hline Lower income than Dutch natives & $-0.546^{* * *}$ & 0.160 \\
\hline Higher income than Dutch natives & 0.121 & 0.198 \\
\hline High importance of income comparison with Turkish immigrants in the Netherlands & -0.135 & 0.179 \\
\hline Lower income than Turkish immigrants in the Netherlands & -0.172 & 0.271 \\
\hline Higher income than Turkish immigrants in the Netherlands & -0.046 & 0.170 \\
\hline High importance of income comparison with other immigrants in the Netherlands & $-0.740 * *$ & 0.326 \\
\hline Lower income than other immigrants in the Netherlands & 0.082 & 0.284 \\
\hline Higher income than other immigrants in the Netherlands & -0.074 & 0.165 \\
\hline $\begin{array}{l}\text { High importance of income comparison with other immigrants } x \text { higher income than } \\
\text { other immigrants (interaction) }\end{array}$ & $0.897 * *$ & 0.413 \\
\hline High importance of income comparison with people in Turkey & -0.031 & 0.143 \\
\hline Lower income than people in Turkey & -0.185 & 0.265 \\
\hline Higher income than people in Turkey & -0.192 & 0.170 \\
\hline Worse living standard than parents & $-0.802 * * *$ & 0.249 \\
\hline Better living standard than parents & $0.501 * * *$ & 0.173 \\
\hline Ln income & 0.114 & 0.140 \\
\hline Life satisfaction five years ago & $0.359 * * *$ & 0.037 \\
\hline Gender & -0.161 & 0.153 \\
\hline Age/10 & -0.129 & 0.469 \\
\hline$(\text { Age } / 10)^{2}$ & 0.014 & 0.057 \\
\hline Generation & $0.316^{*}$ & 0.184 \\
\hline Household size & -0.064 & 0.061 \\
\hline Number of children & -0.096 & 0.093 \\
\hline Widowed & -0.233 & 0.816 \\
\hline Seperated/divorced & $-0.580 * *$ & 0.286 \\
\hline Single & 0.000 & 0.220 \\
\hline Elementary education & 0.353 & 0.295 \\
\hline Secondary education & -0.147 & 0.234 \\
\hline Vocational education & 0.100 & 0.199 \\
\hline Undergraduate education & $0.349 *$ & 0.199 \\
\hline Post-graduate education & $0.744 * *$ & 0.339 \\
\hline Part-time & -0.273 & 0.206 \\
\hline Self-employed & -0.193 & 0.194 \\
\hline Retired & 0.150 & 0.618 \\
\hline Housewife & -0.071 & 0.366 \\
\hline Student & -0.189 & 0.293 \\
\hline Non-working & -0.387 & 0.219 \\
\hline Importance of religion & 0.044 & 0.068 \\
\hline Identification as muslim & 0.160 & 0.149 \\
\hline Identification as Dutch & 0.293 & 0.353 \\
\hline Identification as world citizen & 0.142 & 0.218 \\
\hline Identification as another category & -0.082 & 0.355 \\
\hline
\end{tabular}


Note: $* * *=p<0.01, * *=p<0.05, *=p<0.10$.

\section{Table C.2. OLS estimates of coefficients of all cardinal variables for ethnic reference groups}

\begin{tabular}{|c|c|c|}
\hline $\begin{array}{l}\text { Dependent variable: } \\
\text { Life satisfaction }(0-10)\end{array}$ & $\begin{array}{l}\text { Estimated } \\
\text { coefficient }\end{array}$ & $\begin{array}{l}\text { Standard } \\
\text { error }\end{array}$ \\
\hline Importance of income comparison with Dutch natives & $0.239 * *$ & 0.102 \\
\hline Ln income in comparison to Dutch natives & $0.691 * * *$ & 0.202 \\
\hline Importance of income comparison with Turkish immigrants in the Netherlands & -0.159 & 0.116 \\
\hline Ln income in comparison to Turkish immigrants in the Netherlands & 0.156 & 0.381 \\
\hline (Importance of income comparison with other immigrants) $^{4}$ & $-0.017 *$ & 0.009 \\
\hline Ln income in comparison to other immigrants & -0.266 & 0.358 \\
\hline $\begin{array}{l}\text { (Importance of income comparison with other immigrants })^{4} \mathrm{x} \ln \text { income in comparison } \\
\text { with other immigrants (interaction) }\end{array}$ & 0.012 & 0.007 \\
\hline Importance of income comparison with Turkish people in Turkey & -0.048 & 0.103 \\
\hline Ln income in comparison to Turkish people in Turkey & 0.167 & 0.621 \\
\hline Worse living standard than parents & $-0.817 * * *$ & 0.248 \\
\hline Better living standard than parents & $0.453 * * *$ & 0.171 \\
\hline Ln income & 0.090 & 0.139 \\
\hline Observations & 758 & \\
\hline Adjusted R-squared & 0.374 & \\
\hline
\end{tabular}

Note: $* * *=p<0.01, * *=p<0.05, *=p<0.10$. 
Table C.3. OLS estimates of coefficients of all dummy variables for life-domain reference groups

\begin{tabular}{lll}
\hline $\begin{array}{l}\text { Dependent variable: } \\
\text { Life satisfaction (0-10) }\end{array}$ & $\begin{array}{l}\text { Estimated } \\
\text { coefficient }\end{array}$ & $\begin{array}{l}\text { Standard } \\
\text { error }\end{array}$ \\
\hline High importance of income comparison with colleagues & 0.100 & 0.178 \\
Lower income than colleagues & -0.311 & 0.234 \\
Higher income than colleagues & 0.184 & 0.183 \\
High importance of income comparison with neighbours & -0.021 & 0.247 \\
Lower income than neighbours & $-0.729^{* * *}$ & 0.238 \\
Higher income than neighbours & 0.208 & 0.177 \\
High importance of income comparison with relatives in the Netherlands & $0.467^{* *}$ & 0.201 \\
Lower income than relatives in the Netherlands & -0.083 & 0.242 \\
Higher income than relatives in the Netherlands & $-0.412^{*}$ & 0.214 \\
High importance of income comparison with relatives in other EU countries & $-0.427^{*}$ & 0.245 \\
Lower income than relatives in other EU countries & -0.146 & 0.186 \\
Higher income than relatives in other EU countries & 0.057 & 0.207 \\
High importance of income comparison with relatives in Turkey & $-0.435^{* *}$ & 0.186 \\
Lower income than relatives in Turkey & 0.035 & 0.261 \\
Higher income than relatives in Turkey & -0.045 & 0.178 \\
Worse living standard than parents & $-0.836^{* * *}$ & 0.253 \\
Better living standard than parents & $0.313^{*}$ & 0.182 \\
Ln income & 0.076 & 0.148 \\
\hline Observations & 653 & 0.379 \\
Adjusted R-squared & & \\
\hline Note: & & \\
\hline
\end{tabular}

Note: $* * *=p<0.01, * *=p<0.05, *=p<0.10$. 
Table C.4. OLS estimates of coefficients of all cardinal variables for life-domain reference groups

\begin{tabular}{lll}
\hline $\begin{array}{l}\text { Dependent variable: } \\
\text { Life satisfaction (0-10) }\end{array}$ & $\begin{array}{l}\text { Estimated } \\
\text { coefficient }\end{array}$ & $\begin{array}{l}\text { Standard } \\
\text { error }\end{array}$ \\
\hline Importance of income comparison with colleagues & -0.040 & 0.129 \\
Ln income in comparison to colleagues & 0.477 & 0.327 \\
Importance of income comparison with neighbours & -0.004 & 0.128 \\
Ln income in comparison to neighbours & $1.019^{* * *}$ & 0.378 \\
Importance of income comparison with relatives in the Netherlands & $0.215^{*}$ & 0.125 \\
Income in comparison to relatives in the Netherlands & 0.456 & 0.452 \\
(Income in comparison to relatives in the Netherlands) & 2 & 0.068 \\
Importance of income comparison with relatives in other EU countries & -0.100 & 0.549 \\
(Importance of income comparison with relatives in other EU countries) $)^{2}$ & $-0.346^{* *}$ & 0.143 \\
Ln income in comparison to relatives in other EU countries & 0.206 & 0.285 \\
Importance of income comparison with relatives in Turkey & $-0.308^{* *}$ & 0.126 \\
Ln income in comparison to relatives in Turkey & -0.210 & 0.257 \\
Worse living standard than parents & $0.826^{* * *}$ & 0.247 \\
Better living standard than parents & $0.373^{* *}$ & 0.181 \\
Ln income & 0.100 & 0.149 \\
\hline Observations & 653 & 0.379 \\
Adjusted R-squared & & \\
\hline Note: & & \\
\hline
\end{tabular}

Note: $* * *=\mathrm{p}<0.01, * *=\mathrm{p}<0.05, *=\mathrm{p}<0.10$. 